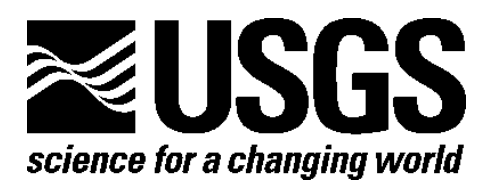

Prepared in cooperation with the Bureau of Reclamation

\title{
Review of Revised Klamath River Total Maximum Daily Load Models from Link River Dam to Keno Dam, Oregon
}

By Stewart A. Rounds and Annett B. Sullivan

Open-File Report 2013-1136

(Reissue of an Administrative Report prepared for the Bureau of Reclamation, 2010)

U.S. Department of the Interior

U.S. Geological Survey 


\section{U.S. Department of the Interior \\ SALLY JEWELL, Secretary}

\section{U.S. Geological Survey \\ Suzette Kimball, Acting Director}

U.S. Geological Survey, Reston, Virginia 2013

For more information on the USGS-the Federal source for science about the Earth,

its natural and living resources, natural hazards, and the environment:

World Wide Web: http://www.usgs.gov

Telephone: 1-888-ASK-USGS

Suggested citation:

Rounds, S.A., and Sullivan, A.B., 2013, Review of revised Klamath River total maximum daily load models from Link River Dam to Keno Dam, Oregon: U.S. Geological Survey Open-File Report 2013-1136, 31 p.

http://pubs.usgs.gov/of/2013/1136/ (Reissue of an Administrative Report prepared for the Bureau of Reclamation, 2010)

Any use of trade, product, or firm names is for descriptive purposes only and does not imply endorsement by the U.S. Government.

Although this report is in the public domain, permission must be secured from the individual copyright owners to reproduce any copyrighted material contained within this report. 


\section{Contents}

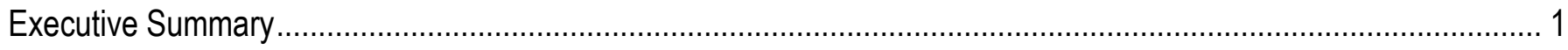

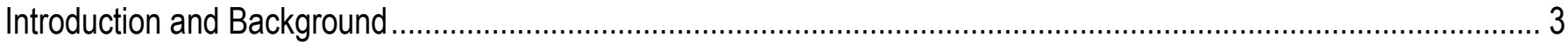

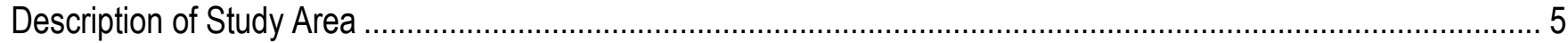

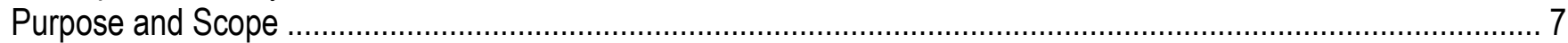

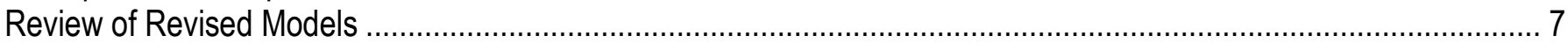

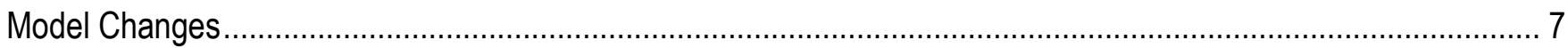

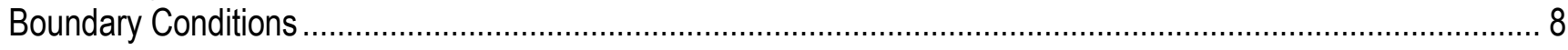

Model Source Code

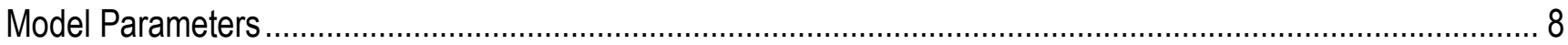

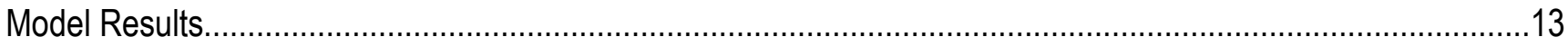

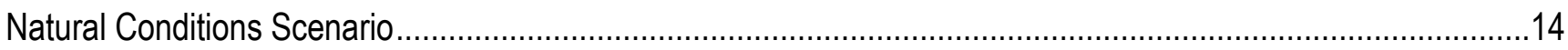

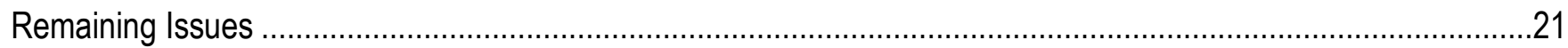

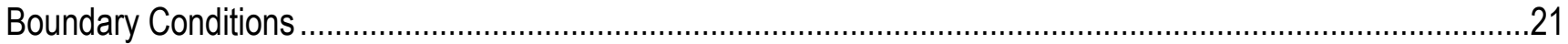

Model Source Code

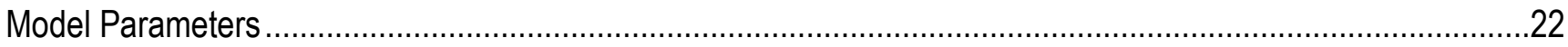

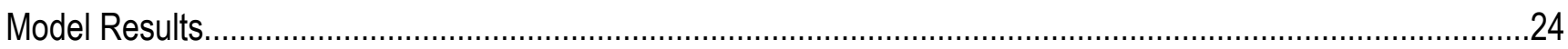

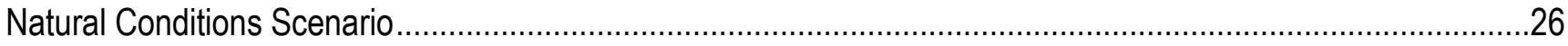

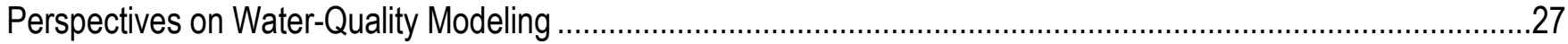

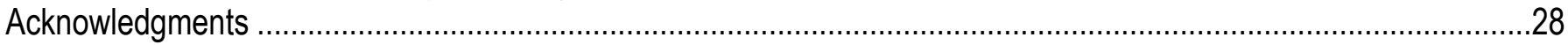

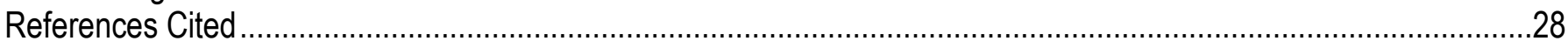

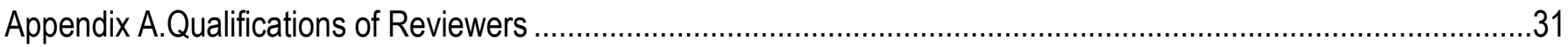

\section{Figures}

Figure 1. Map showing the Klamath River, its major tributaries, and locations of dams on the upper river, Oregon

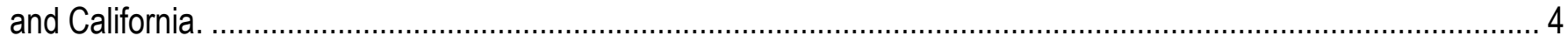

Figure 2. Map showing Link River Dam to Keno Dam reach of the Klamath River, Oregon ...................................... 6

Figure 3. Graphs showing dependence of the rate of sediment oxygen demand (SOD) on water temperature for the original and revised Lake Ewauna to Keno Dam Klamath River TMDL models.

Figure 4. Graph showing dependence of the oxygen rate multiplier on the dissolved oxygen concentration for the Lake Ewauna to Keno Dam Klamath River TMDL model.

Figure 5. Graph showing upstream boundary algae concentrations in the original and revised natural conditions models.

Figure 6. Graph showing upstream boundary labile organic matter concentrations (LDOM + LPOM) in the original and revised natural conditions models.

Figure 7. Graph showing upstream boundary organic matter concentrations (LDOM and LPOM) in the original and revised natural conditions scenarios.

Figure 8. Graph showing sum of organic matter and algae boundary input concentrations in the original and revised natural conditions models.

Figure 9. Graph showing total phosphorus boundary inflow concentrations in the original and revised natural conditions models.

Figure 10. Graph showing dissolved inorganic phosphorus concentrations at the downstream outflow (Keno reef) in the original and revised natural conditions models. 
Figure 11. Graphs showing total phosphorus mean and 1- and 2-standard deviations for the eutrophic and mesotrophic OECD lake classifications.

Figure 12. Graph showing simulated conversion rates from "healthy" to "unhealthy" algae $\left(K_{1}\right)$ and back $\left(K_{2}\right)$ for phytoplankton and epiphyton in the Klamath River TMDL model for Lake Ewauna to Keno Dam, Oregon.

Figure 13. Graphs showing measured and simulated nitrate concentrations in the Klamath River at Keno (Highway 66)

Figure 14. Graphs showing simulated withdrawal rates for the North and Ady Canals for the natural conditions scenario and the year 2000 current conditions scenario.

\section{Tables}

Table 1. Goodness-of-fit statistics for the original and revised Lake Ewauna to Keno Dam models of the Klamath River, Oregon, using results from May 1 through October 31

Table 2. Annual and summer average total phosphorus concentrations in the major inflows and the downstream outflow of the original and revised natural conditions models

\section{Conversion Factors, Datums, and Abbreviations and Acronyms}

Inch/Pound to SI

\begin{tabular}{lll}
\hline \multicolumn{1}{c}{ Multiply } & \multicolumn{1}{c}{ By } & \multicolumn{1}{c}{ To obtain } \\
\hline cubic foot per second $\left(\mathrm{ft}^{3} / \mathrm{s}\right)$ & 0.02832 & cubic meter per second $\left(\mathrm{m}^{3} / \mathrm{s}\right)$ \\
foot (ft) & 0.3048 & meter $(\mathrm{m})$ \\
mile (mi) & 1.609 & kilometer $(\mathrm{km})$ \\
\hline
\end{tabular}

SI to Inch/Pound

\begin{tabular}{lll}
\hline \multicolumn{1}{c}{ Multiply } & \multicolumn{1}{c}{ By } & \multicolumn{1}{c}{ To obtain } \\
\hline gram (g) & 0.03527 & ounce, avoirdupois (oz) \\
meter (m) & 3.281 & foot (ft) \\
square meter per day $\left(\mathrm{m}^{2} / \mathrm{d}\right)$ & 10.76 & square foot per day $\left(\mathrm{ft}^{2} / \mathrm{d}\right)$ \\
\hline
\end{tabular}

Temperature in degrees Celsius $\left({ }^{\circ} \mathrm{C}\right)$ may be converted to degrees Fahrenheit $\left({ }^{\circ} \mathrm{F}\right)$ as follows: ${ }^{\circ} \mathrm{F}=\left(1.8 \times{ }^{\circ} \mathrm{C}\right)+32$.

Concentrations of chemical constituents in water are given in milligrams per liter $(\mathrm{mg} / \mathrm{L})$ or micrograms per liter $(\mu \mathrm{g} / \mathrm{L})$.

\section{Datums}

Vertical coordinate information is referenced to the Upper Klamath Lake Vertical Datum (UKLVD), a local datum established by the Bureau of Reclamation. For purposes of this report, UKLVD - $1.78 \mathrm{ft}=$ NGVD 29. "Elevation," as used in this report, refers to distance above the vertical datum.

Horizontal coordinate information is referenced to the North American Datum of 1983 (NAD 83). 


\section{Acronyms and Abbreviations}

DO dissolved oxygen

DOC dissolved organic carbon

DOM dissolved organic matter

EPA U.S. Environmental Protection Agency

ESP elevation of spillway

FSOD fraction of user-specified sediment oxygen demand

ISS inorganic suspended solids

LDOM labile dissolved organic matter

LPOM labile particulate organic matter

$\mathrm{N} \quad$ nitrogen

ODEQ Oregon Department of Environmental Quality

OM organic matter

P phosphorus

POM particulate organic matter

RDOM refractory dissolved organic matter

RPOM refractory particulate organic matter

SDK sedimentary organic matter decomposition rate

SOD sediment oxygen demand

TDS total dissolved solids

TMDL total maximum daily load

TN total nitrogen

TP total phosphorus

UKL Upper Klamath Lake

USGS U.S. Geological Survey 
This page is intentionally blank. 


\title{
Review of Revised Klamath River Total Maximum Daily Load Models from Link River Dam to Keno Dam, Oregon
}

\author{
By Stewart A. Rounds and Annett B. Sullivan
}

\section{Executive Summary}

Flow and water-quality models are being used to support the development of Total Maximum Daily Load (TMDL) plans for the Klamath River downstream of Upper Klamath Lake (UKL) in south-central Oregon. For riverine reaches, the RMA-2 and RMA-11 models were used, whereas the CE-QUAL-W2 model was used to simulate pooled reaches. The U.S. Geological Survey (USGS) was asked to review the most upstream of these models, from Link River Dam at the outlet of UKL downstream through the first pooled reach of the Klamath River from Lake Ewauna to Keno Dam. Previous versions of these models were reviewed in 2009 by USGS. Since that time, important revisions were made to correct several problems and address other issues. This review documents an assessment of the revised models, with emphasis on the model revisions and any remaining issues.

The primary focus of this review is the 19.7-mile Lake Ewauna to Keno Dam reach of the Klamath River that was simulated with the CE-QUAL-W2 model. Water spends far more time in the Lake Ewauna to Keno Dam reach than in the 1-mile Link River reach that connects UKL to the Klamath River, and most of the critical reactions affecting water quality upstream of Keno Dam occur in that pooled reach. This model review includes assessments of years 2000 and 2002 current conditions scenarios, which were used to calibrate the model, as well as a natural conditions scenario that was used as the reference condition for the TMDL and was based on the 2000 flow conditions. The natural conditions scenario included the removal of Keno Dam, restoration of the Keno reef (a shallow spot that was removed when the dam was built), removal of all point-source inputs, and derivation of upstream boundary water-quality inputs from a previously developed UKL TMDL model.

This review examined the details of the models, including model algorithms, parameter values, and boundary conditions; the review did not assess the draft Klamath River TMDL or the TMDL allocations. Attention to the details of a model is one of the best ways to identify potential problems, correct them if possible, and begin to assess the magnitude of potential model errors and uncertainty. Model users need to determine the level of acceptable uncertainty associated with their objectives, identify all sources of potential uncertainty (model uncertainty, data uncertainty, etc.), and assess their approach and results accordingly. In the draft Klamath River TMDL, the Oregon Department of Environmental Quality identified the upstream boundary conditions as the largest source of uncertainty for both the current and natural conditions scenarios, not the model algorithms or choice of model parameters. We agree that the upstream boundary conditions are one of the largest, if not the largest, source of model uncertainty; therefore, the derivation of upstream boundary conditions may be more important to the TMDL than some other model-related issues identified in this review.

The revised models contain a number of changes, some of which were done to solve small problems and are largely inconsequential to model results, but others of which are important and affect model predictions of instream concentrations. A consistent version of the model is now applied to all 
scenarios, and an error in the source code was corrected that had inadvertently discarded 20 percent of the incoming solar radiation in the original model. The baseline light-extinction coefficient for water was decreased and set to a consistent and defensible value across all models of reservoir reaches. Inconsistencies among the values of certain parameters in the original models, such as the ammonia nitrification rate and the decomposition rates of organic matter, have been eliminated, although the reasoning behind the final selections was not documented. The dependence of the rate of sediment oxygen demand (SOD) on temperature was modified such that the SOD rate was substantially decreased at temperatures less than $20^{\circ} \mathrm{C}$, causing the model to predict higher dissolved oxygen (DO) concentrations in spring, autumn, and winter. Although that change to the temperature dependence function was done to make the function more similar to the model's default, this change was not accompanied by any documentation of recalibration or sensitivity exercises. The maximum SOD rate for the 2002 current conditions scenario was decreased from 3.0 grams per square meter per day $\left(\mathrm{g} / \mathrm{m}^{2} / \mathrm{d}\right)$ in the original model to $2.0 \mathrm{~g} / \mathrm{m}^{2} / \mathrm{d}$ in the revised model, a considerable adjustment that appears to have been needed to offset effects of a change to another variable (O2LIM) that would have resulted in a substantial increase in the effective SOD rate for 2002. A 50-percent decrease in the SOD rate over a 2-year period, however, is not likely to be mirrored by field measurements, so this change may be compensating for some process that is not represented correctly in the DO budget for the current conditions scenarios.

Several important changes were made to the natural conditions scenario. First, the elevation of the Keno reef was corrected; the elevation specified in the original model was 1 foot too high, which affected the volume of the pooled reach and the travel time through it. The most important changes to this scenario were to the upstream boundary inputs of organic matter and algae, which affect incoming fluxes of nitrogen and phosphorus. Algal biomass inputs were increased by approximately 60 percent during summer because of a change in the way those inputs were derived from results of the UKL TMDL model. Non-algal organic matter inputs were decreased, particularly in summer to correct a problem attributed to double-counting of phosphorus in the original inputs. The distribution of non-algal organic matter was changed from 20 percent dissolved in the original model to 90 percent dissolved in the revised model in response to review comments and published data. The overall sum of algal biomass and non-living organic matter was decreased, which resulted in lower inputs of total phosphorus and nitrogen. Total phosphorus inputs were less than $0.03 \mathrm{mg} / \mathrm{L}$, and although the inputs were derived from selected results of the UKL TMDL model, these concentrations seem too low to be representative of a historically eutrophic system surrounded by extensive wetlands, peat soils, and a groundwater system high in phosphorus. The draft TMDL states that the upstream boundary conditions are the greatest source of uncertainty, greater than any uncertainty associated with the models. Efforts to improve existing models of algal growth and nutrient cycling in UKL, therefore, would provide a substantial benefit to downstream modeling efforts on the Klamath River.

Although many improvements were made in revising the Klamath River TMDL models, some issues and uncertainties remain. Several errors in the model source code remain, but do not affect model results for this application as long as certain options and rates are not changed; future users of these models should be aware of these issues. Although the distribution of dissolved and particulate organic matter was modified for the natural conditions scenario, that distribution was not changed for the current conditions scenarios. Recent data on that distribution and the likely rates of organic matter decomposition could be used to improve these models in the future. Nitrate predictions at Keno (Highway 66) still are too high for the current conditions scenarios; future efforts should re-evaluate the model's denitrification rates and the release rate of ammonia from anoxic sediments. Possibly the most important of the remaining issues are tied to the two-state (healthy/unhealthy) hypothesis for the algae 
population that was coded into the model. Some of the rates and conversion functions could be refined to make them more acceptable; currently, the published literature does not support the concept of moderately low dissolved-oxygen concentrations as a stressor of algae in the ranges used by the model. More research is needed before these algorithms can be truly tested. The algorithms currently appear to help the model fit the patterns in the available data, and that is useful and perhaps sufficient for some purposes, but those algorithms are not truly predictive or reliable for certain purposes until they can be tested through well-designed experiments and research.

In summary, the TMDL models used to simulate Link and Klamath Rivers from Link River Dam to Keno Dam were revised to fix several problems and address various issues. The resulting models are an improvement over those that were reviewed by USGS in 2009, and represent a useful advance in the simulation of a complex system that is difficult to model. However, several issues remain that cause increased uncertainty in the model results. Depending on the objectives of the modeling, now or in the future, these remaining issues could be more or less important. For the Klamath River TMDL, the upstream boundary conditions may be a larger source of uncertainty than the concerns with model algorithms and model parameters identified in this review. Efforts to re-evaluate the available models of algal growth and nutrient cycling in UKL would be highly beneficial to downstream modeling efforts in the Klamath River.

\section{Introduction and Background}

The Klamath River flows from Upper Klamath Lake (UKL) in south-central Oregon past a series of dams into northern California, where the river eventually empties into the Pacific Ocean near the town of Klamath (fig. 1). The Klamath River does not meet certain water-quality standards as specified by the States of Oregon and California, and both States have placed the Klamath River on their list of impaired water bodies. As required by the Federal Clean Water Act, these States and the U.S. Environmental Protection Agency (EPA) are in the process of creating Total Maximum Daily Load (TMDL) plans in an effort to bring the water quality of the river into compliance with standards. In Oregon, TMDL issues for the Klamath River are temperature, ammonia toxicity, dissolved oxygen, $\mathrm{pH}$, and algae (chlorophyll). In California, the TMDL issues in the Klamath River are temperature, nutrients, organic enrichment, dissolved oxygen, sedimentation, and algal toxins, depending on the specific reach.

Water-quality models are being used to form the foundation of Oregon's TMDL program for the Klamath River. The models of Link and Klamath Rivers upstream of Keno Dam were originally developed by Dr. Michael Deas of Watercourse Engineering, Inc. (Watercourse) for the relicensing of a series of PacifiCorp dams (Watercourse Engineering, Inc., 2004). For the Lake Ewauna to Keno Dam reach of the Klamath River, Dr. Deas built on a previous model by CH2M-Hill and Dr. Scott Wells of Portland State University (CH2M-Hill and Wells, 1995). The Watercourse models then were modified for the purpose of TMDL development by Tetra Tech, Inc., under contract to the Oregon Department of Environmental Quality (ODEQ), the California North Coast Regional Water Quality Control Board, and EPA (Tetra Tech, Inc., 2009a). 


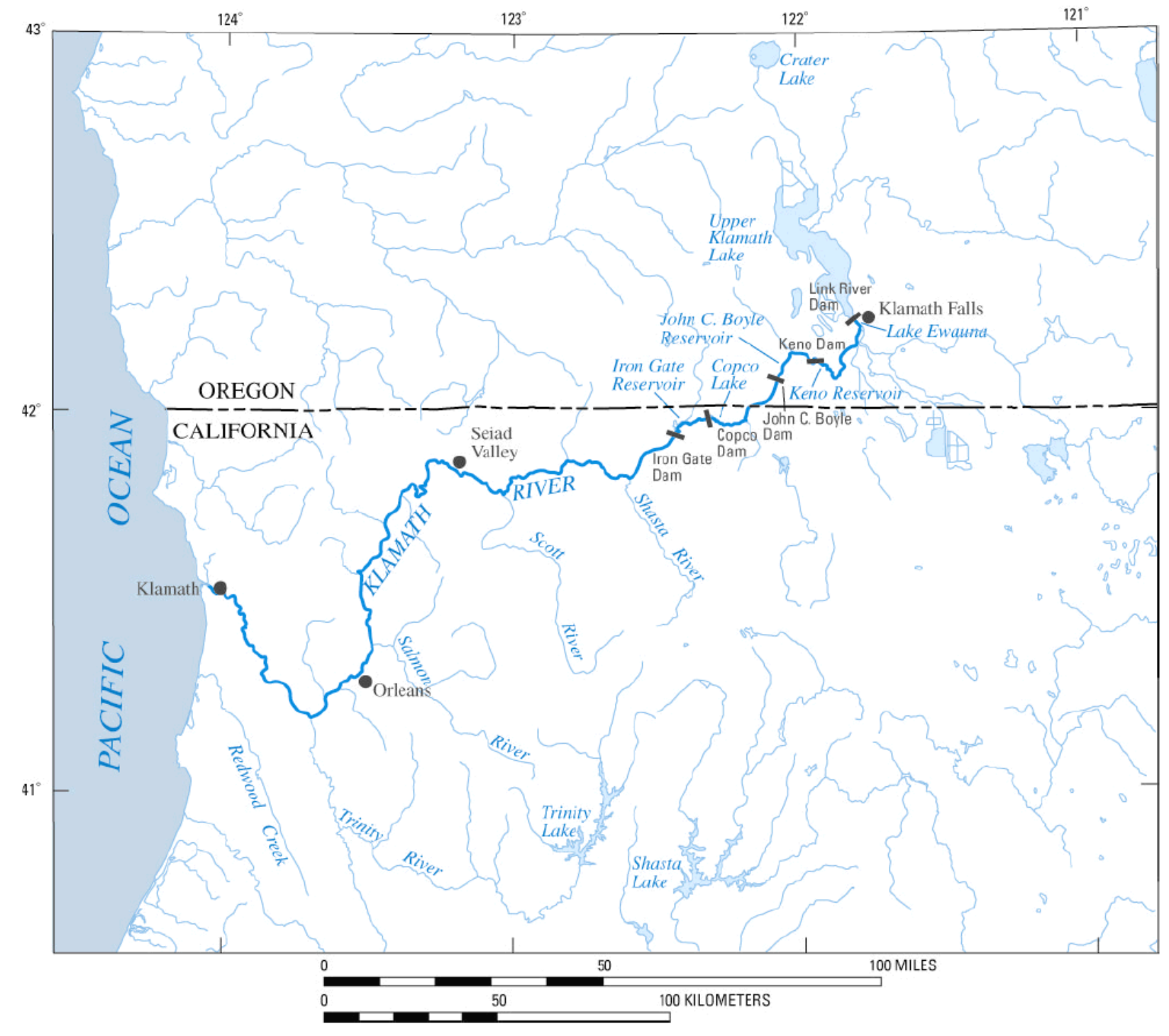

Figure 1. Map showing the Klamath River, its major tributaries, and locations of dams on the upper river, Oregon and California. (Map from Risley and Rounds, 2006.)

The development of TMDLs often relies on a historical, reference, or hypothetical condition that helps regulators identify an acceptable level of anthropogenic impact under the applicable water-quality standards. Because such a reference condition may not exist at present and historical data may not be available, models typically are used to estimate the characteristics of the reference condition. For the Klamath River TMDL, a "natural conditions" scenario was constructed to simulate water quality in the river under a condition without dams and with improved upstream water-quality conditions. The natural conditions scenario relied on results from models used previously for the UKL TMDL (Walker, 2001). This natural conditions scenario is important because it forms part of the foundation of the TMDL; this and related model scenarios typically are used as the basis for regulatory actions or goals, such as establishment of limits on point-source nutrient discharges or restoration of a more natural flow, channel shape, or riparian condition. 


\section{Description of Study Area}

This model review includes the two most upstream models used in the Klamath River TMDL: (1) Link River from Link River Dam to Lake Ewauna and (2) Lake Ewauna to Keno Dam. The Link River Dam to Keno Dam reach is approximately $21 \mathrm{mi}$ long and has an annual average flow of about 1,600 $\mathrm{ft}^{3} / \mathrm{s}$ at the streamflow-gaging station 1.4 mi downstream of Keno Dam. The Lake Ewauna to Keno Dam reach is a 19.7-mi reservoir-like reach that runs from Link River (the outlet of UKL) to Keno Dam (fig. 2). That reach has a typical width of 330-1,300 ft, a typical depth of 10-20 ft, and undergoes periodic thermal stratification. The Klamath River upstream of Keno Dam is greatly affected by water-quality conditions in UKL, where large populations of blue-green algae dominate the water quality of the lake in summer (Hoilman and others, 2008). This reach of the river has been classified as having "very poor" water quality during summer, as quantified by the Oregon Water Quality Index (Mrazik, 2006). A water-quality investigation of this reach was initiated by the Bureau of Reclamation in 2006 in partnership with the U.S. Geological Survey (USGS) and Watercourse; selected data from the study are available online (Sullivan and others, 2008, 2009; see http://or.water.usgs.gov/proj/keno_reach/data.html). 


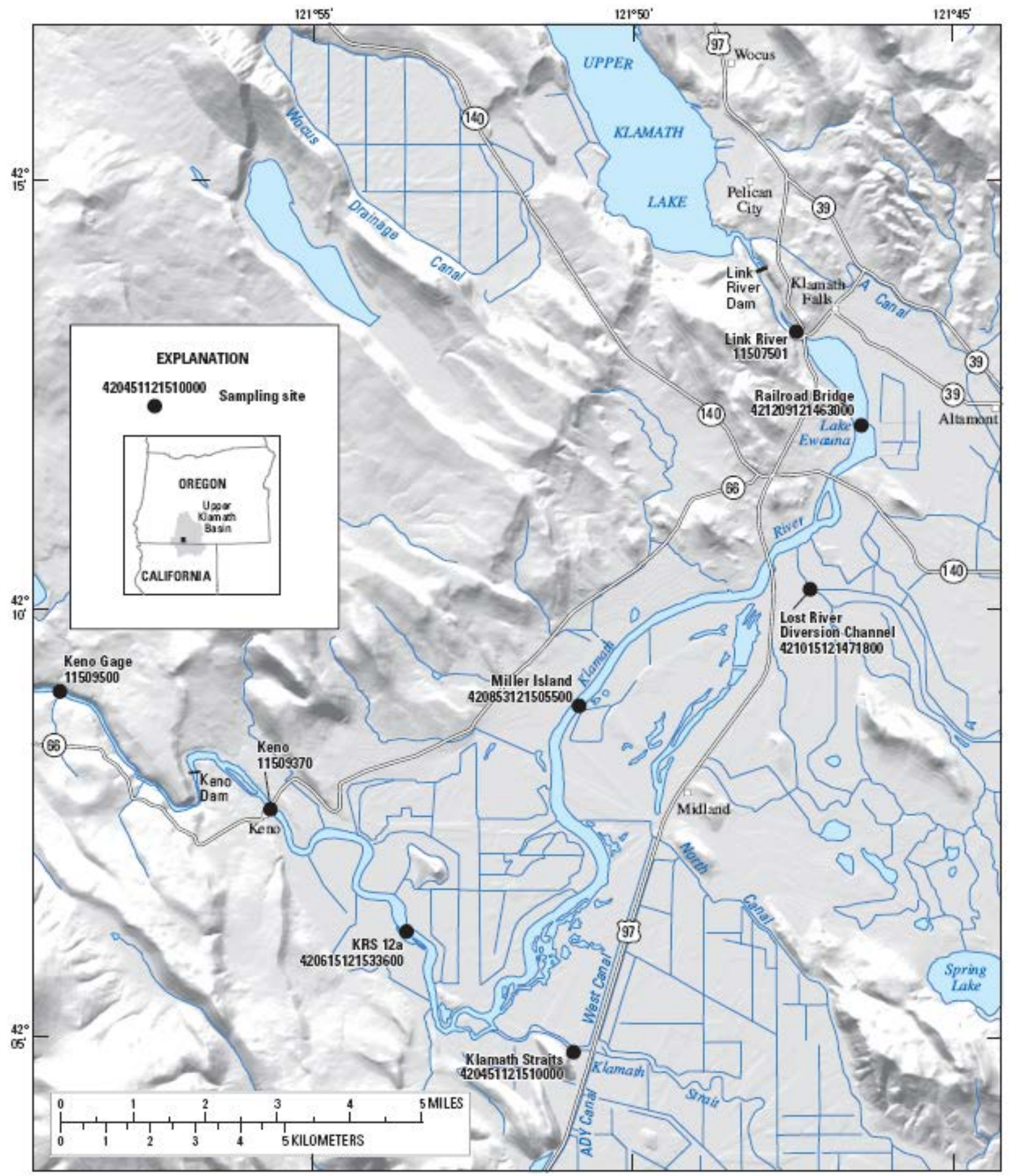

Figure 2. Map showing Link River Dam to Keno Dam reach of the Klamath River, Oregon. Sites shown are the locations of data-collection stations used by the Bureau of Reclamation and the U.S. Geological Survey. 


\section{Purpose and Scope}

The purpose of this report is to document a review of revised flow and water-quality models constructed for the 21-mi Link River Dam to Keno Dam reach of the Klamath River, just downstream of UKL in south-central Oregon (fig. 2). The 1-mi Link River reach was simulated with the RMA-2 and RMA-11 models (King, 2002; 2003). Output from those models provided upstream boundary conditions for a CE-QUAL-W2 model (Cole and Wells, 2002) of the 19.7-mi Lake Ewauna to Keno Dam reach. Earlier versions of these models were reviewed previously by USGS (Rounds and Sullivan, 2009), but the models have since been revised to correct certain problems and address issues raised during the June-August 2009 and December 2009-February 2010 public comment period for the California Klamath River TMDL.

The objective of this review was to assess the technical merit of the revised models and determine whether any issues remain unaddressed from the 2009 USGS review of the original models. This review does not assess the draft Klamath River TMDL, the draft TMDL allocations, or the methodology used to determine those allocations. Although the models are being used to help construct TMDL plans for the Klamath River, this assessment was of the models, not the draft TMDL.

The Lake Ewauna to Keno Dam CE-QUAL-W2 model of the Klamath River is the primary focus of this review for several reasons. The reach simulated by that model includes the great majority of the length of the UKL to Keno Dam reach and accounts for most of the travel time. It also is the reach where the most important water-quality problems and processes occur - the travel time in Link River is short enough that fewer of the critical changes occur there. The models reviewed included several scenarios:

- Current conditions, year 2000

- Current conditions, year 2002

- Natural conditions

The current (existing) conditions models were developed for calendar years 2000 and 2002. The natural conditions model was based on the current conditions year 2000 model, with adjustments to remove Keno Dam and point-source inflows, restore the Keno reef (a shallow spot removed when Keno Dam was built), and set boundary inputs to median loading conditions from the 1995 UKL TMDL model. Models, documentation, and model source code for this review were provided to USGS by Tetra Tech and ODEQ.

\section{Review of Revised Models}

This review is divided into several sections. First, the late-2009 revisions made to the models are identified and discussed. Second, a selection of remaining issues from the original model review are described along with the reasons these issues remain important and potential opportunities for improvement. Lastly, some perspective on the issues raised in this and the original model review is provided so that readers might better understand how to interpret the information in this review.

\section{Model Changes}

Several important revisions were made to the Link-to-Keno Klamath River TMDL models to address issues that were identified during the June-August 2009 public comment period for the California TMDL and to refine the model scenarios. This section of the model review identifies the changes that were made and assesses the potential effects of those changes. 


\section{Boundary Conditions}

- Boundary temperatures. The 2009 USGS model review suggested that it might be wise to incorporate some seasonal variation into the distributed tributary, stormwater, and point-source accretion temperature inputs, where such variation was not already present (comment A2-Rounds and Sullivan, 2009). Seasonal variation has been incorporated into the revised model's distributed tributary temperatures for the year 2000 current conditions scenario; seasonal variation already was present in the 2002 distributed tributary. The stormwater and point-source accretion temperature inputs, however, remain at a constant $12^{\circ} \mathrm{C}$ all year. These inputs can be large at certain times of the year, and some variation in the temperatures of these sources is likely, so it would be helpful to incorporate some amount of seasonal variation into those inputs. Although the stormwater and pointsource accretion temperatures are constant, this setting is likely to have only a minor effect on model results in mid-summer because those inputs are small at that time.

\section{Model Source Code}

- Version control and documentation. The 2009 USGS model review noted that different versions of the model source code were used for the current conditions and natural conditions scenarios (comment C3-Rounds and Sullivan, 2009). This inconsistency has been corrected, and all revised model scenarios were run with the same model code and program.

- SC10 error. The Lake Ewauna to Keno Dam CE-QUAL-W2 model source code was revised to remove a problem that was identified in the 2009 USGS model review (comment C4-Rounds and Sullivan, 2009). In that review, it was discovered that 20 percent of the incoming short-wave solar radiation was discarded through a change in the model source code embodied in a variable named SC10. Errors in the application of this change to the model source code caused additional inconsistencies in the handling of the vertical heat flux associated with light penetration, among other problems.

This problem has been corrected in the revised model. The SC10 variable and all FORTRAN statements related to this error have been removed from the model source code used for the Lake Ewauna to Keno Dam model. The existence of this coding error apparently had been an oversight; therefore, its removal was appropriate.

Although the correction of this error is an important change, the implication of this change on simulated water temperatures is difficult to assess because other revisions affecting the heat budget also were made, such as changes in the value of the baseline light-extinction coefficient. The overall performance of the model with respect to water temperature is assessed and discussed in the section "Model Results."

\section{Model Parameters}

- Algae. Both the original and revised models simulate algae and epiphyton in two different states"healthy" and "unhealthy" - where the unhealthy fraction is stressed by exposure to low dissolved oxygen (DO) concentrations and is modeled with rates of growth, respiration, excretion, and mortality that are different from those used for the healthy algae fraction. The 2009 USGS review commented on several aspects of the representation of healthy/unhealthy algae in the model (comment D1—Rounds and Sullivan, 2009).

The model allows algae in the healthy group to become stressed and the stressed algae to recover (Tetra Tech, Inc., 2009a). Healthy algae in the model are converted to an unhealthy state at a user- 
specified rate that depends on the simulated DO concentration, with a greater rate of conversion at lower DO concentrations. Similarly, the unhealthy algae are converted to a healthy state at a different user-specified rate that increases at higher DO concentrations. The 2009 USGS model review noted that the healthy/unhealthy conversion rates and their functional dependence on DO were different for phytoplankton as opposed to epiphyton, but that no justification was provided for the different conversion rates. In the revised model, the conversion rates and their DO dependence for epiphyton were changed to make them identical to those specified for phytoplankton (other than the healthy-tounhealthy cut-off at a DO of $6 \mathrm{mg} / \mathrm{L}$, which is implemented for phytoplankton but not for epiphyton). The original review comment was not meant to suggest that these rates and DO dependencies should be identical; it is entirely possible that if this sort of stress actually occurs in the river, it might be manifested differently for epiphyton as compared to phytoplankton.

Discussions with the TMDL modeling team indicated that these changes to the healthy/unhealthy conversion rates for epiphyton were made for the sake of consistency. The healthy/unhealthy hypothesis and the details of its implementation are relatively new and untested, with little research or field data to set the values of model parameters other than through model calibration. Data on epiphyton were not available for the Lake Ewauna to Keno Dam reach for the years modeled, and the effect of epiphyton on overall model results is minimal. Using a consistent set of healthy/unhealthy conversion rates for phytoplankton and epiphyton, therefore, seems a reasonable choice. If epiphyton play a minimal role in affecting water quality in this reach of the Klamath River, which seems likely based on best available information, then these changes to the DO/epiphyton relation should have little effect on overall model results.

- Sediment oxygen demand. The 2009 USGS model review pointed out that the zero-order rate of sediment oxygen demand (SOD) used in the original model, $3.0 \mathrm{~g} / \mathrm{m}^{2} / \mathrm{d}$, was significantly higher than the SOD rate measured in-situ by USGS in this reach of the Klamath River (median $=1.8 \mathrm{~g} / \mathrm{m}^{2} / \mathrm{d}$ at $20^{\circ} \mathrm{C}$, Doyle and Lynch, 2005; comment D2-Rounds and Sullivan, 2009). Laboratory measurements of SOD rates from cores collected in the Lake Ewauna reach of the Klamath River have varied greatly and include relatively moderate rates $\left(0.97-1.96 \mathrm{~g} / \mathrm{m}^{2} / \mathrm{d}\right.$, Raymond and Eilers, 2004) as well as relatively high rates (2.68-3.61 g/m²/d, Eilers and Raymond, 2005).

In the revised model, the year 2000 current conditions scenario retained a maximum SOD rate of $3.0 \mathrm{~g} / \mathrm{m}^{2} / \mathrm{d}(\mathrm{SOD}=3.0, \mathrm{FSOD}=1.0)$, but the year 2002 current conditions scenario was revised to decrease the maximum SOD rate to $2.0 \mathrm{~g} / \mathrm{m}^{2} / \mathrm{d}(\mathrm{SOD}=3.0, \mathrm{FSOD}=0.667)$. The natural conditions SOD rate remained at $1.42 \mathrm{~g} / \mathrm{m}^{2} / \mathrm{d}(\mathrm{SOD}=3.0, \mathrm{FSOD}=0.473)$. In addition, the value of the SODK1 parameter, one of several that specify the temperature dependence of the SOD rate, was decreased for all revised models from 0.5 to 0.1 , resulting in a greatly decreased SOD rate at temperatures less than about $20^{\circ} \mathrm{C}$ (fig. 3). 

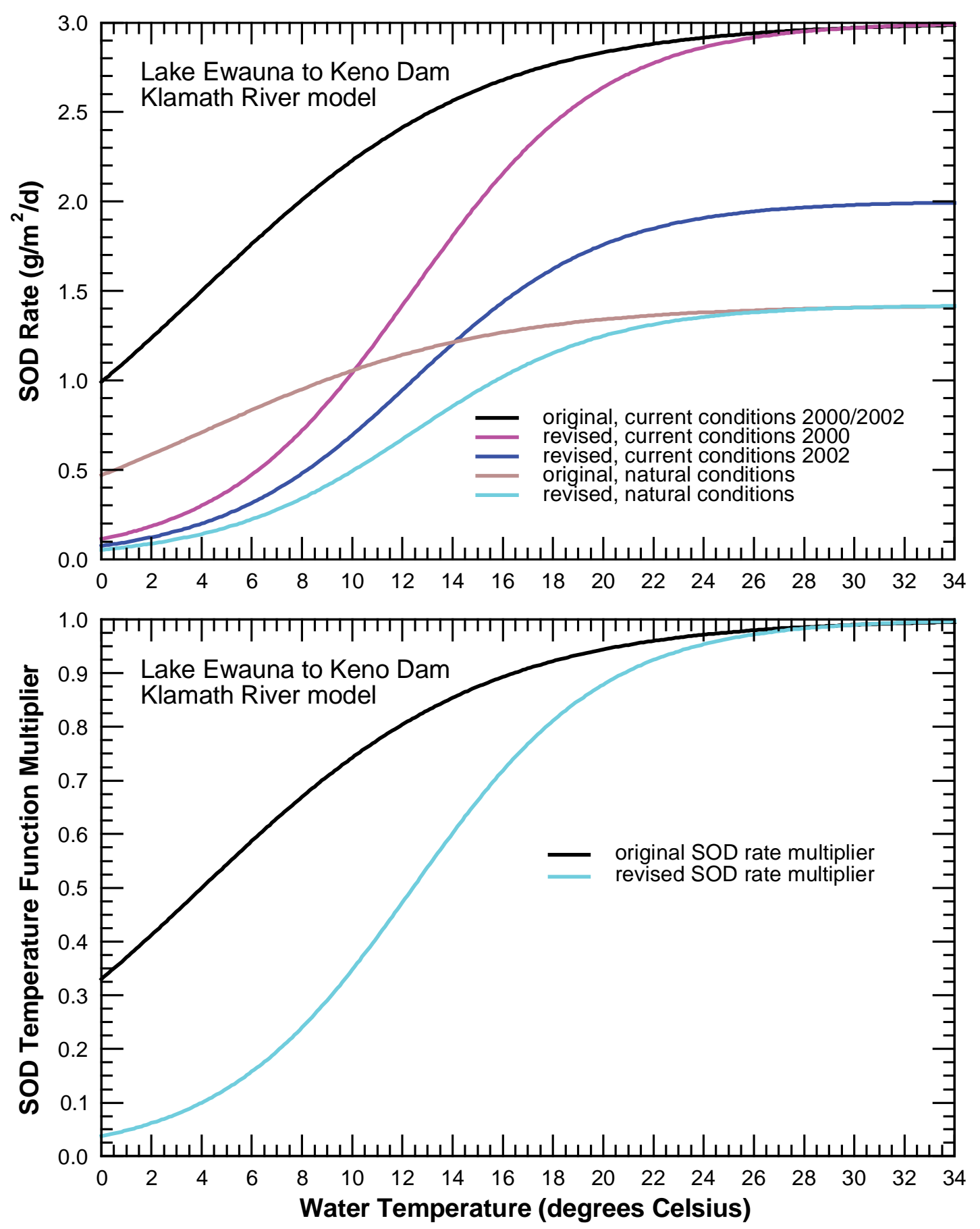

Figure 3. Graphs showing dependence of the rate of sediment oxygen demand (SOD) on water temperature for the original and revised Lake Ewauna to Keno Dam Klamath River TMDL models. Water temperatures in this reach of the Klamath River range from 0 to $26^{\circ} \mathrm{C}$ during the year.

Discussions with the TMDL modeling team indicated that the change in the SODK1 parameter was done to make the temperature dependence of the SOD rate more consistent with the default functionality of the model, where the suggested value is 0.1 (Cole and Wells, 2002). The value used in the original version of the model (0.5) apparently was a remnant of calibration testing. Few measurements of the SOD rate have been made in the Klamath River at temperatures well below 
$20^{\circ} \mathrm{C}$, so the temperature dependence of this process is largely left to model calibration and information gleaned from published literature. The large decrease in the temperature rate multiplier for SOD at temperatures less than $20^{\circ} \mathrm{C}$ should result in higher simulated DO concentrations outside of the warm summer period, which is exactly what the model results show. It would be useful to perform a sensitivity analysis to determine an optimal temperature dependence for SOD for the cooler spring, autumn, and winter seasons.

The decreased SOD rate for the revised 2002 current conditions scenario was explained as used to reflect potential interyear variability (California North Coast Regional Water Quality Control Board, 2010), but no justification was provided for retaining the relatively high SOD rate of 3.0 $\mathrm{g} / \mathrm{m}^{2} / \mathrm{d}$ for the year 2000 current conditions scenario. Measurements and published research suggest that SOD rates typically do not decrease by one-third (3.0 to $2.0 \mathrm{~g} / \mathrm{m}^{2} / \mathrm{d}$ ) over a 2-year period, but tend to be more constant over time in the absence of large changes in environmental conditions (Rounds and Doyle, 1997). Variation in the loading of OM from UKL might indeed have an effect on the SOD rate just downstream in Lake Ewauna. Measurements of the SOD rate in the Lake Ewauna to Keno Dam reach in 2003 (Doyle and Lynch, 2005), however, were similar to rates measured in UKL in spring and summer of 1999 (Wood, 2001), indicating that significant year-toyear variation in the SOD rate is unlikely. If the 2002 SOD rate had to be decreased by a factor of one-third to achieve an acceptable DO calibration, then perhaps the SOD rate is inadvertently compensating for some other poorly represented DO-related process in the model. Through additional analyses and model calibration, it should be possible to determine a set of interannually consistent DO-related model parameters that achieve a reasonable calibration for both 2000 and 2002.

- Parameter value consistency among models. The 2009 USGS model review identified several parameters for which inconsistent values were specified for the year 2000 and 2002 current conditions scenarios and the natural conditions scenario (comment D3-Rounds and Sullivan, 2009). These inconsistencies existed for the nitrification rate (NH4DK), dissolved oxygen half-saturation constant (O2LIM), labile dissolved organic matter (DOM) and particulate organic matter (POM) decomposition rates (LDOMDK, LPOMDK), and the POM settling rate (POMS). The revised models have been changed to use consistent values for all these parameters. The only remaining inconsistency among the revised model parameters is the maximum SOD rate, as described in the previous comment.

Documentation was not provided for the (now consistent) values selected for NH4DK, O2LIM, LDOMDK, LPOMDK, and POMS in the revised models. All these parameters are relatively important to the simulation of ammonia, DO, and OM; therefore, it seems reasonable that a set of sensitivity analyses or model calibration exercises should have been conducted and documented to determine the best set of final values for these parameters.

The change in the value of O2LIM (from 2.0 to $0.1 \mathrm{mg} / \mathrm{L}$ ) for the 2002 current conditions model has important ramifications for the simulation of many processes in the model, including DO, ammonia, and nitrate. A multiplier based on O2LIM is used in the model to determine how oxygendependent rate processes vary as a function of the DO concentration. Reactions that consume oxygen, for example, become inactive under low-DO conditions because the O2LIM-dependent rate multiplier approaches zero as the DO concentration approaches zero (fig. 4). The rate multiplier in figure 4 can be viewed as the fractional value of a temperature-adjusted reaction rate. At a DO concentration of $2.0 \mathrm{mg} / \mathrm{L}$, for example, the SOD rate would be one-half of its temperature-adjusted value if O2LIM were set to $2.0 \mathrm{mg} / \mathrm{L}$, but would be about 95 percent of its temperature-adjusted 
value if O2LIM were set to $0.1 \mathrm{mg} / \mathrm{L}$. The use of an O2LIM of $2.0 \mathrm{mg} / \mathrm{L}$ in the original 2002 current conditions scenario was an oversight; a value of $0.1 \mathrm{mg} / \mathrm{L}$ is far more reasonable and is the recommended value from the CE-QUAL-W2 user manual (Cole and Wells, 2002). The result, however, is that many oxygen-dependent reaction rates in the 2002 current conditions scenario are noticeably higher in the revised model. This change results in a higher effective SOD rate, which might explain the apparent need to decrease the maximum SOD rate from 3.0 to $2.0 \mathrm{~g} / \mathrm{m}^{2} / \mathrm{d}$ for 2002 . A higher ammonia nitrification rate, which results from the decreased O2LIM value, also explains the increase in simulated nitrate concentrations in mid-summer for the 2002 scenario relative to the previous version of the model. Ensuring a consistent O2LIM value of $0.1 \mathrm{mg} / \mathrm{L}$ for all scenarios is an important model revision and has a large effect on many modeled rates. Additional analyses to document these effects and assess the potential need for additional model calibration seem warranted.

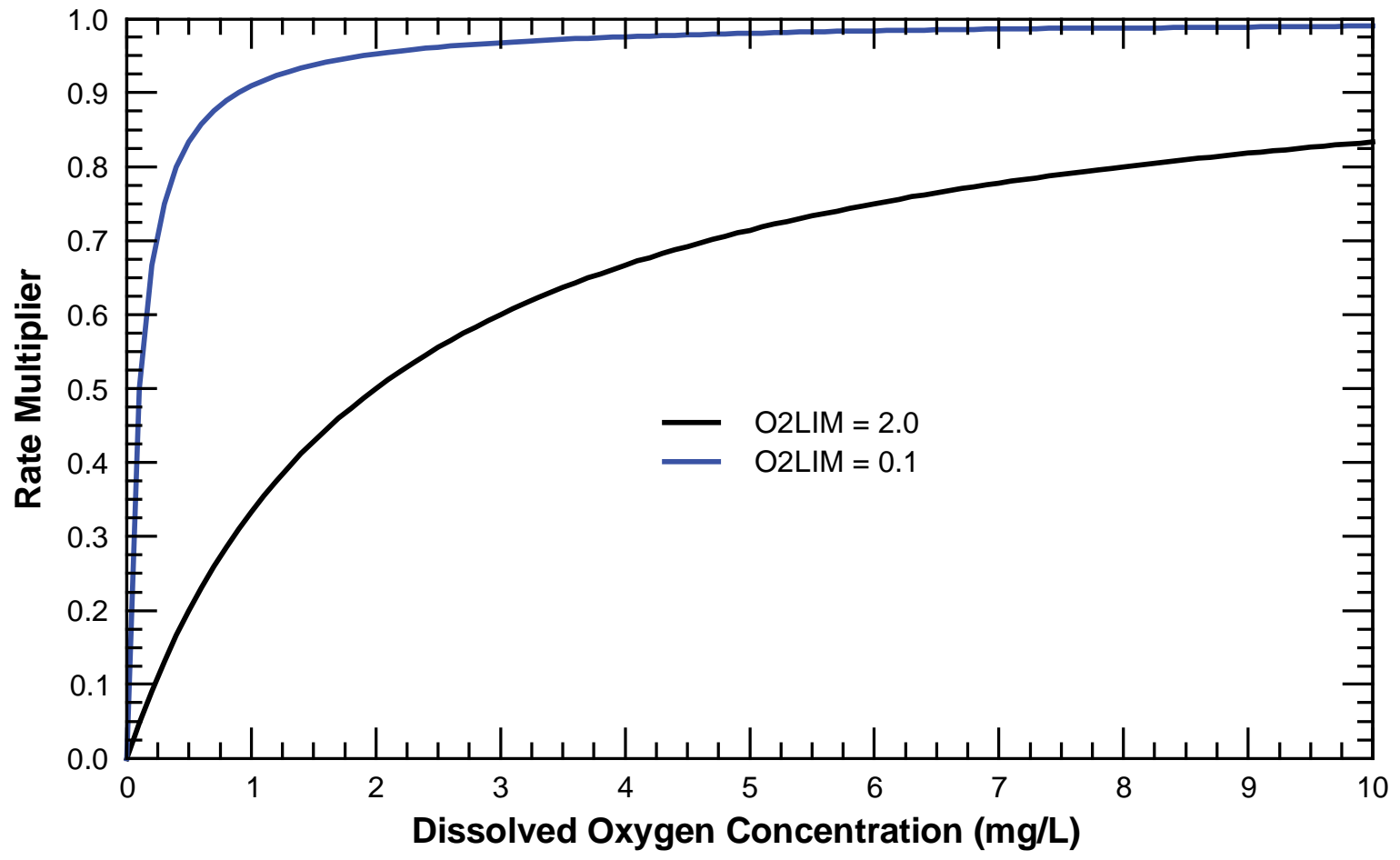

Figure 4. Graph showing dependence of the oxygen rate multiplier on the dissolved oxygen concentration for the Lake Ewauna to Keno Dam Klamath River TMDL model. A value of $0.1 \mathrm{mg} / \mathrm{L}$ is used for the revised models and was used for the original models except for the 2002 current conditions scenario, which used a value of $2.0 \mathrm{mg} / \mathrm{L}$.

- Light extinction. The baseline light-extinction coefficient for water was decreased from $0.60 / \mathrm{m}$ in the original Lake Ewauna to Keno Dam model to $0.45 / \mathrm{m}$ in the revised model. This revision was done to address a consistency issue identified in the original Klamath River TMDL models, in which this baseline extinction coefficient was given different values in the several reservoir models (comment Db-Rounds and Sullivan, 2009). A value of $0.45 / \mathrm{m}$ for the baseline light-extinction coefficient is within the range of acceptable values for this parameter (Cole and Wells, 2002). A smaller baseline light-extinction coefficient allows more of the short-wave light energy to penetrate deeper into the water column, thus altering the temperature distribution in the epilimnion and the depth of the thermocline at times. 
Model Results

- Error statistics. The 2009 USGS model review recommended that goodness-of-fit statistics be reported because such statistics can be useful as one means of assessing model performance (comment E2-Rounds and Sullivan, 2009). The documentation for the revised model now includes goodness-of-fit statistics in addition to graphical comparisons of modeled and measured values (Tetra Tech, Inc., 2009a).

The mean error statistics in the revised model documentation appear to have been computed as measured minus modeled, although this is not stated in the documentation (Tetra Tech, Inc., 2009a, appendix E). This convention is the reverse of the typical method; it is more common to compute the mean error as modeled minus measured so that the sign of the result gives an indication of the mean bias of the model. Therefore, when a mean error of $0.15^{\circ} \mathrm{C}$ is reported for the revised year 2000 current conditions scenario at Miller Island, it means that the model has a slight negative bias on the order of $0.15^{\circ} \mathrm{C}$ (see Tetra Tech, Inc., 2009a, appendix E). It would be more intuitive for the reader if the signs of the mean errors were reversed; regardless, the convention (modeled minus measured, or measured minus modeled) should be stated in the documentation.

In order to examine changes in model performance, goodness-of-fit statistics for water temperature and DO were calculated as part of this review for both the original and revised models for May 1 through October 31 at two sites (table 1). Results show a slight improvement in the mean absolute error for the simulation of water temperature, but a slight degradation in the mean absolute error for the simulation of DO at Keno for 2000 and 2002. The mean absolute error can be thought of as the magnitude of typical model uncertainty for any data point.

Table 1. Goodness-of-fit statistics for the original and revised Lake Ewauna to Keno Dam models of the Klamath River, Oregon, using results from May 1 through October 31.

[Model results were compared to measurements taken from 1 meter below the river surface. Site locations are shown in figure 2. Mean error is defined as modeled minus measured. Abbreviations: ${ }^{\circ} \mathrm{C}=$ degrees Celsius; $\mathrm{mg} / \mathrm{L}=\mathrm{milligrams}$ per liter]

\begin{tabular}{|c|c|c|c|c|c|c|c|c|}
\hline \multirow[b]{2}{*}{ Parameter } & \multirow[b]{2}{*}{ Site } & \multirow[b]{2}{*}{ Year } & \multicolumn{3}{|c|}{ Original model } & \multicolumn{3}{|c|}{ Revised model } \\
\hline & & & $\begin{array}{l}\text { Mean } \\
\text { Error }\end{array}$ & $\begin{array}{l}\text { Mean } \\
\text { Absolute } \\
\text { Error }\end{array}$ & $\begin{array}{c}\text { Root } \\
\text { Mean } \\
\text { Square } \\
\text { Error }\end{array}$ & $\begin{array}{l}\text { Mean } \\
\text { Error }\end{array}$ & $\begin{array}{l}\text { Mean } \\
\text { Absolute } \\
\text { Error }\end{array}$ & $\begin{array}{l}\text { Root } \\
\text { Mean } \\
\text { Square } \\
\text { Error }\end{array}$ \\
\hline \multirow{4}{*}{$\begin{array}{c}\text { Water } \\
\text { temperature } \\
\left({ }^{\circ} \mathrm{C}\right)\end{array}$} & \multirow{2}{*}{$\begin{array}{l}\text { Miller } \\
\text { Island }\end{array}$} & 2000 & 0.1 & 1.1 & 1.5 & -0.2 & 1.1 & 1.5 \\
\hline & & 2002 & 0.4 & 1.1 & 1.5 & 0.2 & 0.9 & 1.4 \\
\hline & \multirow{2}{*}{ Keno } & 2000 & 0.4 & 0.8 & 1.0 & 0.2 & 0.7 & 0.9 \\
\hline & & 2002 & 0.8 & 0.9 & 1.1 & -0.6 & 0.8 & 1.0 \\
\hline \multirow{4}{*}{$\begin{array}{c}\text { Dissolved } \\
\text { oxygen } \\
\text { (mg/L) }\end{array}$} & \multirow{2}{*}{$\begin{array}{l}\text { Miller } \\
\text { Island }\end{array}$} & 2000 & -0.5 & 1.9 & 2.5 & -0.1 & 1.9 & 2.6 \\
\hline & & 2002 & 0.4 & 2.1 & 2.7 & -0.1 & 2.2 & 2.9 \\
\hline & \multirow{2}{*}{ Keno } & 2000 & -0.7 & 1.6 & 2.1 & -0.1 & 1.8 & 2.4 \\
\hline & & 2002 & 0.0 & 2.1 & 2.7 & -0.5 & 2.4 & 3.1 \\
\hline
\end{tabular}


It is not entirely straightforward to interpret these goodness-of-fit statistics in light of the revisions made to the models. For example, several important changes were made to the heat budget formulation. The original model had a higher baseline light extinction coefficient, which would tend to convert short-wave solar energy into heat closer to the water surface. In contrast, the original model also had an error that discarded 20 percent of the incoming short-wave solar energy, which would tend to keep the river surface cooler. The result is that the revised model produces 1-m temperatures that are slightly cooler than those of the original model—thus the slightly lower mean errors for water temperature. The mean error is a measure of overall model bias-positive if model predictions tend to be greater than the measured data. The original mean errors show a slight positive bias, indicating that the river was simulated to be slightly too warm near the surface-these goodness-of-fit statistics were computed from measurements and model simulations at 1-m below the surface.

The goodness-of-fit statistics for DO also are difficult to interpret. Given the decreased SOD rates in the revised model at lower temperatures, one might expect simulated DO concentrations in the revised model to be larger outside of the warm summer period, if all other influences were similar. The mean errors for DO indicate that the revised model produces slightly higher DO concentrations in 2000 than the original model, but lower concentrations overall in 2002. Simulated DO concentrations are the result of many influences, however, and many processes affecting DO were changed in the revised models.

\section{Natural Conditions Scenario}

- Keno reef flows. The original natural conditions scenario specified an incorrect value (1,244.82 m) for the spillway elevation (ESP) of the Keno reef. Derivation of the spillway equation showed that the reef elevation should have been 1,244.5 m (comment F2-Rounds and Sullivan, 2009). This discrepancy apparently was due to the use of a feet-to-meters conversion factor with an insufficient number of significant digits. The revised natural conditions scenario uses the correct spillway elevation, 1,244.5 m. This change should allow the model to more accurately simulate stage, velocity, and travel time in the Lake Ewauna to Keno reach.

- Natural conditions initial concentrations. In the original natural conditions scenario, the initial water-quality concentrations were set higher than the initial boundary inputs, closer to concentrations in the current conditions scenarios (comment Fa-Rounds and Sullivan, 2009). This was not a particularly important concern because the initial conditions are rapidly replaced by effects of incoming boundary conditions in these model scenarios. Regardless, the revised model was adjusted so that the initial water-quality concentrations were more similar to the boundary conditions of the natural conditions scenario.

- Natural conditions inflow TDS. Boundary condition concentrations for total dissolved solids (TDS) for the Lost River Diversion Channel and the Klamath Straits Drain were set to zero in the original natural conditions scenario. This was identified as an unrealistic condition in the 2009 USGS model review (comment F3-Rounds and Sullivan, 2009). In the revised natural conditions scenario, the TDS boundary condition concentration for these inflows was changed to $100 \mathrm{mg} / \mathrm{L}$, which is more consistent with the expected range of TDS concentrations for these inflows. TDS concentrations in the model have a minor effect on water density and $\mathrm{pH}$ computations; this change should not greatly affect model predictions of water temperature, nutrients, DO, algae, or OM. 
- Natural conditions ISS. Boundary condition concentrations for inorganic suspended solids (ISS) were decreased in the revised natural conditions scenario (3 mg/L) compared to the original natural conditions scenario $(15 \mathrm{mg} / \mathrm{L})$. The implications of this change are not readily apparent, other than a reduced light extinction where the ISS remain suspended. Effects on more important water-quality constituents such as temperature, nutrients, DO, algae, and OM are likely to be minimal or inconsequential.

- Natural conditions OM, N, and P. For the natural conditions scenario, concentrations of organic matter (OM), nitrogen (N), phosphorus (P), and other water-quality constituents for inflows from Link River, Lost River Diversion Channel, and Klamath Straits Drain were derived from results of the UKL TMDL model. The 2009 USGS model review suggested that the concentrations of DOM, $\mathrm{N}$, and $\mathrm{P}$ in those inflows were lower than one might expect based on the historically eutrophic conditions in UKL and its surrounding wetlands (comments F4 and F5-Rounds and Sullivan, 2009).

In the revised natural conditions scenario, concentrations of most of the dissolved inflow constituents, such as dissolved P, ammonia, nitrate, DO, dissolved inorganic carbon, and alkalinity were unchanged from the original natural conditions scenario. Concentrations of algae, labile particulate organic matter (LPOM), and labile dissolved organic matter (LDOM), however, all of which contain $\mathrm{N}$ and $\mathrm{P}$, were changed. These changes were done to make the TP inputs to the revised model consistent with results from the UKL TMDL model. These changes affect the total incoming flux of nutrients and the simulated downstream concentrations of DO, algae, OM, and nutrients.

The general seasonal pattern of inputs for algae was retained, but higher concentrations were specified in the revised model (range: $0.9-4.0 \mathrm{mg} / \mathrm{L}$ ) than in the original model (range: $0.5-2.5$ $\mathrm{mg} / \mathrm{L}$ ) (fig. 5). In the original model, incoming algae concentrations were calculated from chlorophyll results of the UKL TMDL model using an algae:chlorophyll $a$ mass ratio of 67 (Tetra Tech, Inc., written commun., 2009). For the revised model, incoming algae concentrations were derived from algal P results of the UKL TMDL model using an algal biomass:P mass ratio of 180 (Tetra Tech, Inc., 2009b).

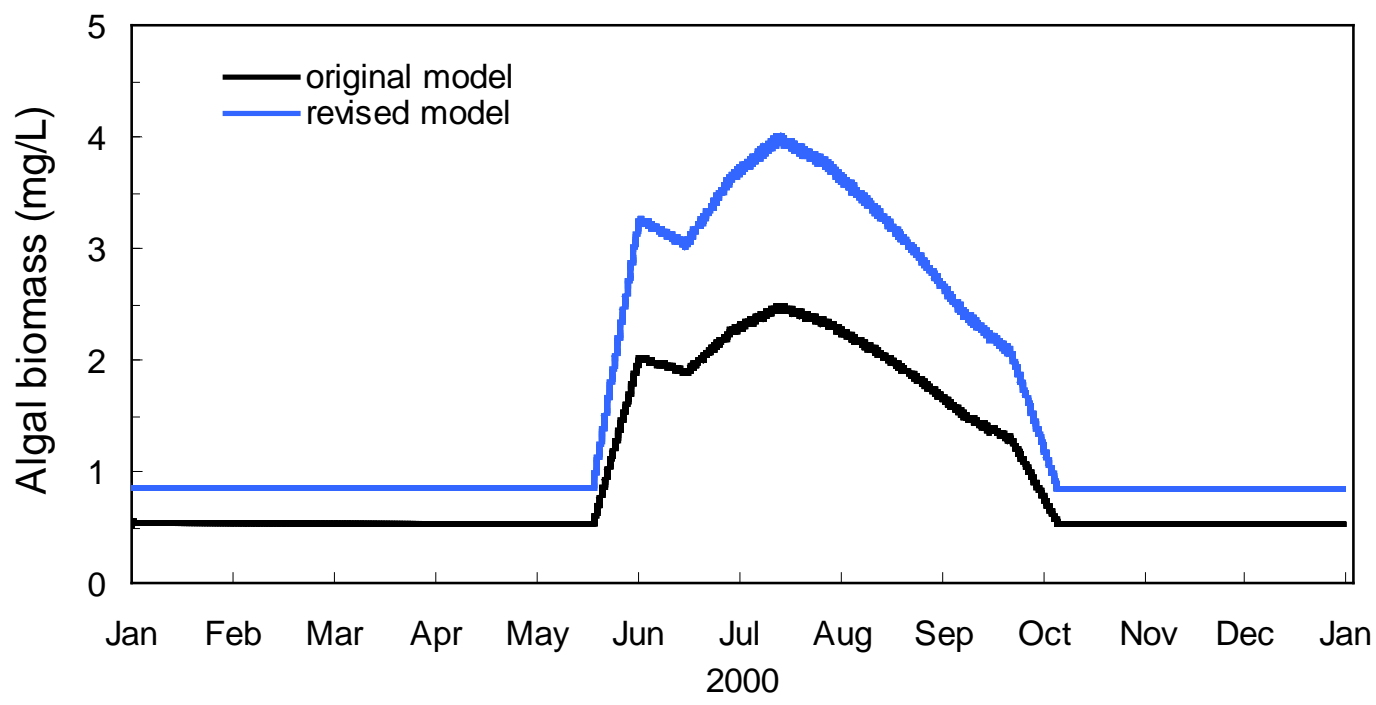

Figure 5. Graph showing upstream boundary algae concentrations in the original and revised natural conditions models. 
With respect to OM boundary inputs in the natural conditions scenario, the sum of LDOM and LPOM was decreased in the revised model (range: 0.1-3.0 mg/L) compared to that in the original model (range: 2.1-3.8 mg/L) (fig. 6). The refractory OM inputs (RDOM and RPOM) were set to zero in both the original and revised models. Documentation for the original (Tetra Tech, Inc., written commun., 2009) and revised (Tetra Tech, Inc., 2009b) models both state that these OM concentrations were derived from UKL TMDL model results for organic P, using an OM:OP mass ratio of 180. Discussions with the TMDL modeling team indicated that part of this change in OM loading was to correct a mistake in the original boundary conditions, the derivation of which may have double-counted a portion of the P load. The result, however, is that the seasonal pattern in OM was changed greatly, with little OM present in mid-summer at the same time that algal biomass concentrations are highest. Patterns in the data from recent years do not show low concentrations of $\mathrm{OM}$ in Link River in mid-summer when algal biomass concentrations are highest (Sullivan and others, 2008, 2009), and it seems strange that the seasonal pattern in non-living OM should be opposite to the pattern in the algae.

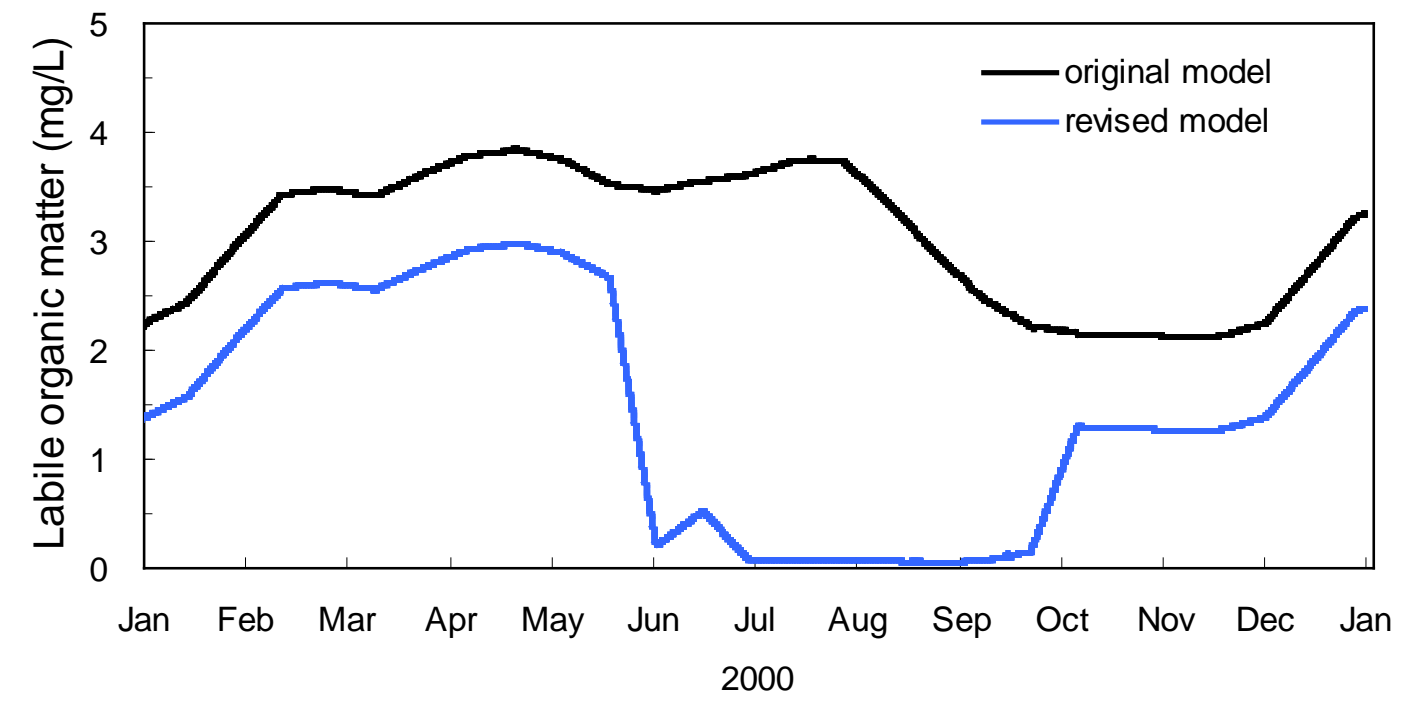

Figure 6. Graph showing upstream boundary labile organic matter concentrations (sum of LDOM and LPOM) in the original and revised natural conditions models.

Total OM concentrations in the revised model are composed of both particulate (LPOM, range: 0-0.3 mg/L) and dissolved (LDOM, range: $0.1-2.7 \mathrm{mg} / \mathrm{L}$ ) forms, with roughly 90 percent of the OM in the dissolved fraction (fig. 7), based on information from Thurman (1985). The 2009 USGS model review noted that inflow DOM concentrations for the original natural conditions scenario were less than $0.8 \mathrm{mg} / \mathrm{L}(0.4 \mathrm{mg} / \mathrm{L}$ as dissolved organic carbon [DOC], using a DOC:DOM mass ratio of 0.45$)$, and that those concentrations were less than what one might expect in a system with extensive surrounding wetlands (comment F4-Rounds and Sullivan, 2009). In the revised model, the annual average inflow DOM concentration was increased in winter, spring, and autumn, up to a maximum of $2.7 \mathrm{mg} / \mathrm{L}$ (1.2 $\mathrm{mg} / \mathrm{L}$ as DOC). Increasing the natural conditions inflow DOM concentration is an improvement in simulating the historical Klamath River, but the maximum model inflow concentration of $1.2 \mathrm{mg} / \mathrm{L}$ as DOC is still well below the range of values cited by Thurman (1985) for rivers and lakes (2-10 mg/L as DOC) and wetlands (10-60 mg/L as DOC). 


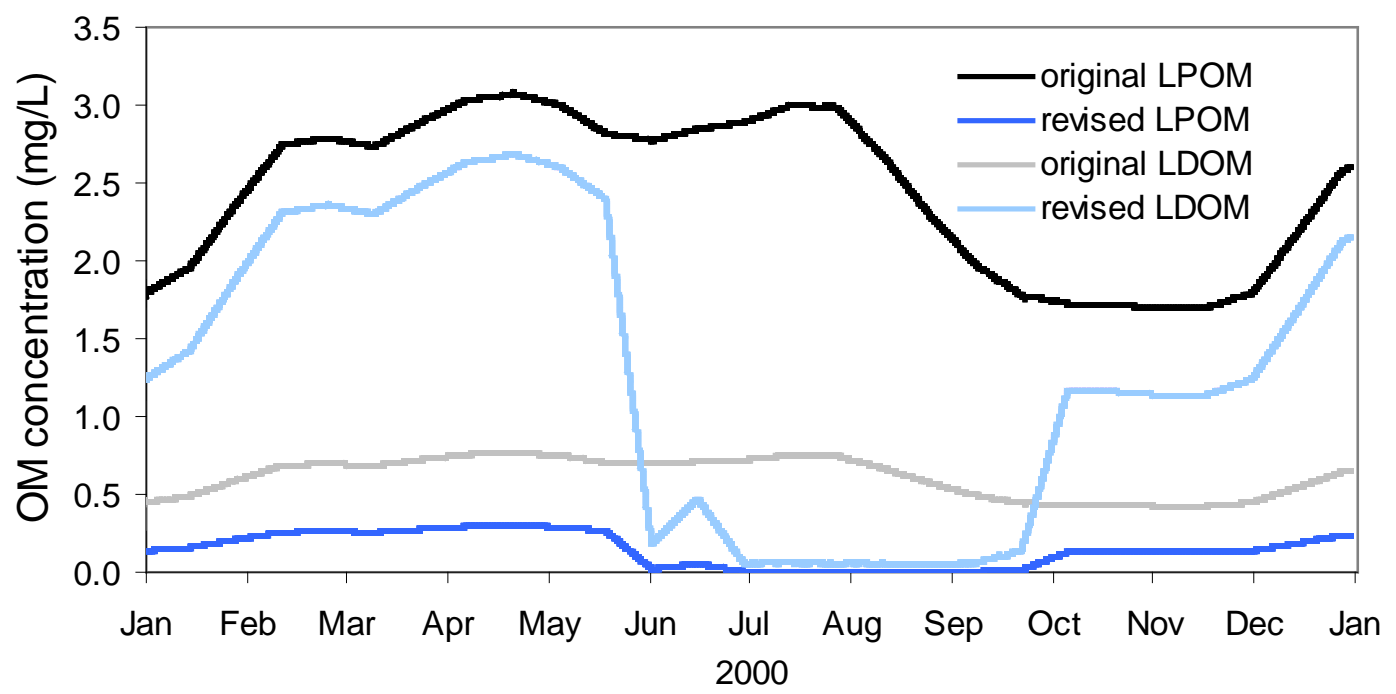

Figure 7. Graph showing upstream boundary organic matter concentrations (LDOM and LPOM) in the original and revised natural conditions scenarios.

The revised OM concentrations in the natural conditions scenario have a different seasonal pattern from the original natural conditions scenario, and a pattern that does not seem consistent with expected patterns. The revised POM and DOM concentrations are low in summer, both with concentrations less than $0.1 \mathrm{mg} / \mathrm{L}$. As mentioned previously, these concentrations are lower than those that might be expected in a system such as UKL. Considering all types of OM inputs (algae plus LDOM and LPOM), the revised natural conditions scenario has lower input concentrations compared to the original natural conditions scenario (fig. 8), which should result in higher DO concentrations downstream because of decreased decomposition of $\mathrm{OM}$.

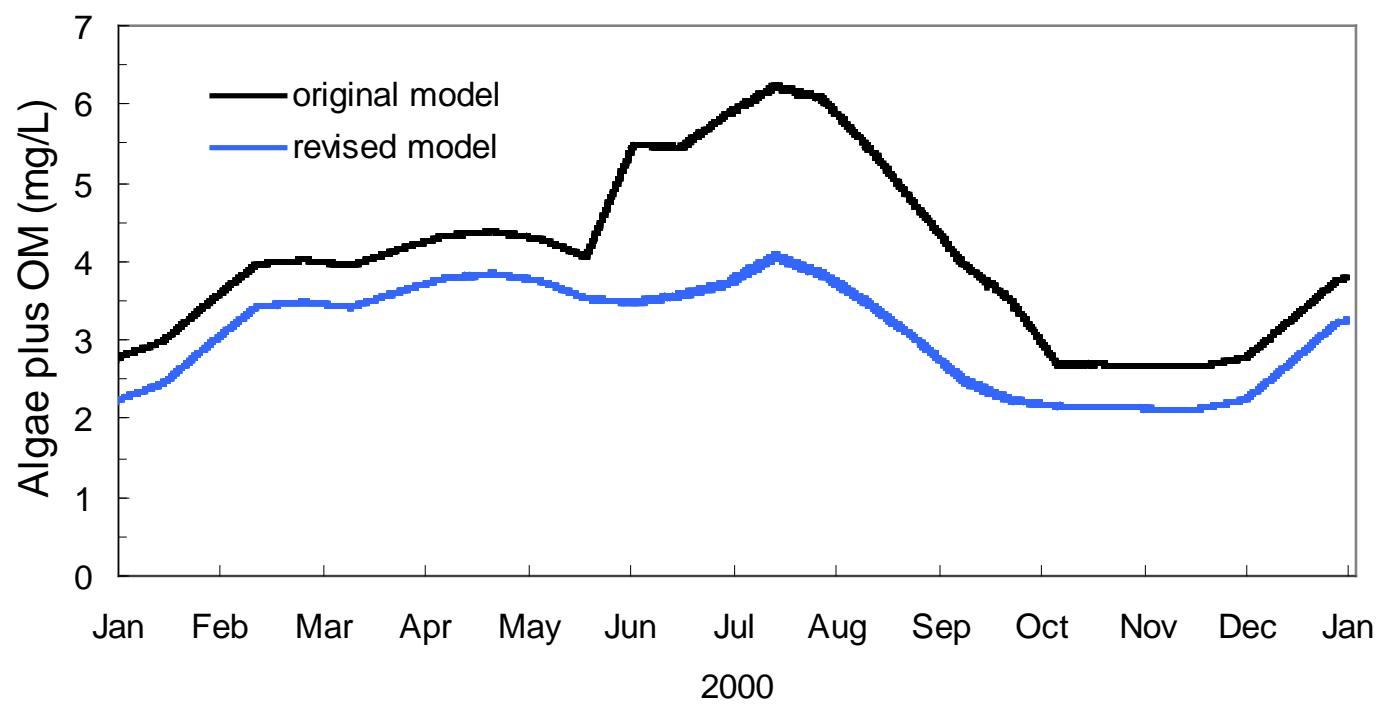

Figure 8. Graph showing sum of organic matter and algae boundary input concentrations in the original and revised natural conditions models. 
By decreasing OM inputs and keeping dissolved nutrient fluxes the same, the overall boundary fluxes of N, P, and carbon were decreased in the revised natural conditions model. Total P concentrations are easily calculated as the sum of dissolved orthophosphate and $\mathrm{P}$ in algae and OM, where the latter two components were computed from upstream boundary algae, LDOM, and LPOM concentrations and the P:algae and P:OM mass ratios specified in the model. The TP concentrations in the boundary inflows of the revised model are lower than those in the original model (fig. 9).

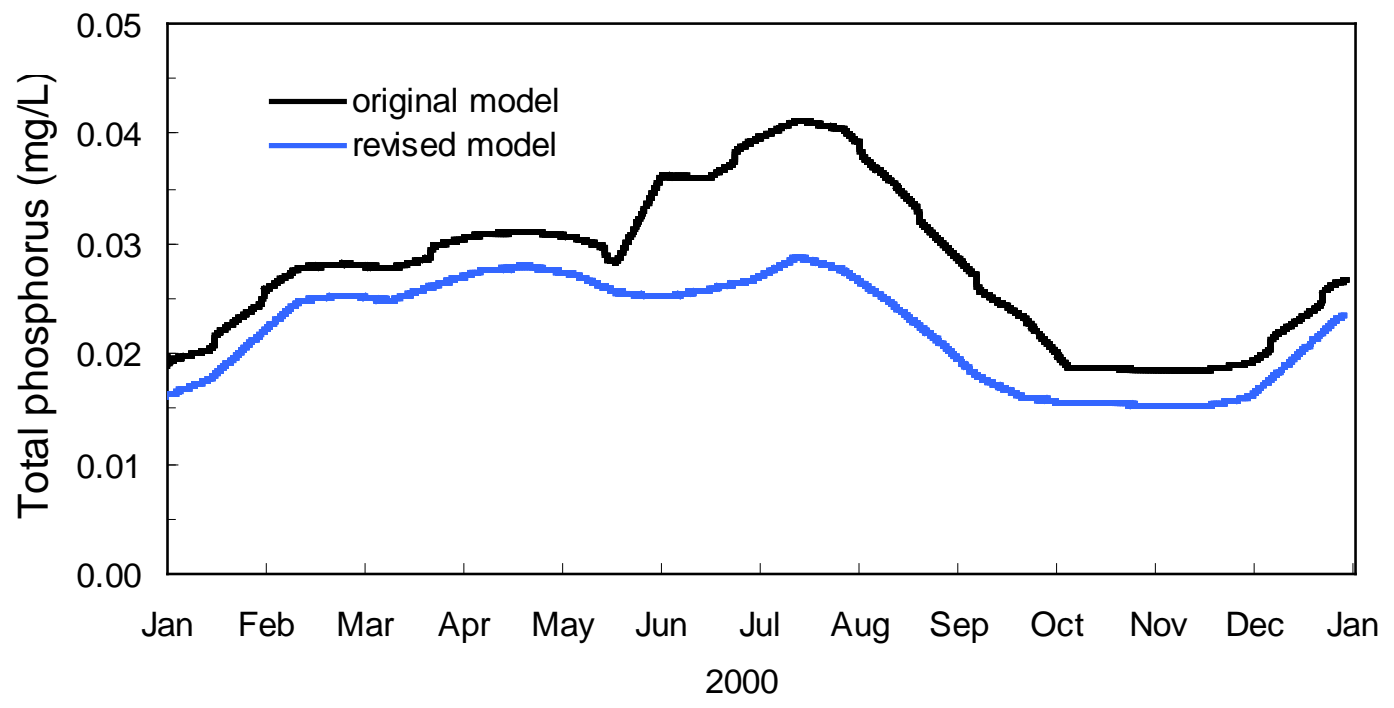

Figure 9. Graph showing total phosphorus boundary inflow concentrations in the original and revised natural conditions models.

Largely because of the decreased boundary input concentrations, simulated TP concentrations at the downstream end of the model at Keno reef are lower in the revised natural conditions scenario than in the original natural conditions scenario (table 2). Similarly, lower inputs of OM and higher inputs of algae, along with instream processes within the Link-to-Keno reach, combine to produce differences in dissolved nutrient concentrations at the downstream outflow. Dissolved inorganic P concentrations, for example, did not change in the upstream inflow but are lower at Keno reef in the revised natural conditions scenario compared to the original natural conditions scenario (fig. 10). 
Table 2. Annual and summer average total phosphorus concentrations in the major inflows and the downstream outflow of the original and revised natural conditions models.

[Abbreviation: $\mathrm{mg} / \mathrm{L}=$ milligrams per liter]

\begin{tabular}{lcc}
\hline & $\begin{array}{c}\text { Original natural conditions } \\
\text { model }\end{array}$ & $\begin{array}{c}\text { Revised natural conditions } \\
\text { model }\end{array}$ \\
\cline { 2 - 3 } Time period & Total P (mg/L) & Total P (mg/L) \\
\hline (Link River, Lost River Diversion Channel, Klamath Straits Drain) \\
annual average (Jan-Dec) & 0.028 & 0.023 \\
summer average (June-Aug) & 0.037 & 0.026 \\
& Outflow & \\
annual average (Jan-Dec) & (at Keno reef) & 0.016 \\
summer average (June-Aug) & 0.024 & 0.012 \\
\hline
\end{tabular}

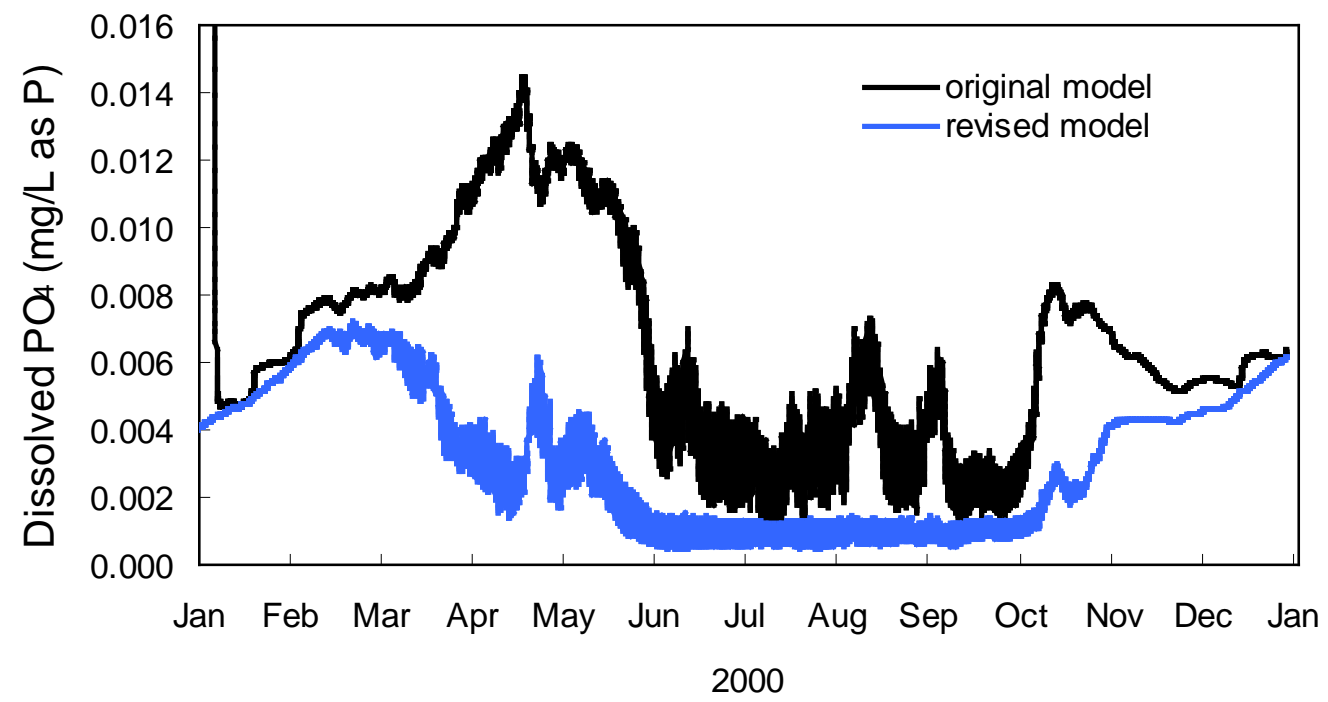

Figure 10. Graph showing dissolved inorganic phosphorus concentrations at the downstream outflow (Keno reef) in the original and revised natural conditions models.

The natural conditions inflow concentrations of TP (table 2) were based on UKL TMDL model results for 1995 (Tetra Tech, Inc., 2009b) that simulated a 40-percent reduction in P loading (Walker, 2001). Other years, 1992-98, also were simulated for the UKL TMDL, but results for 1995 were selected for the Klamath River TMDL model inputs (Tetra Tech, Inc., 2009b). The rationale for that decision is explained in the draft TMDL (Oregon Department of Environmental Quality, 2010). Phosphorus concentrations from the 1995 UKL TMDL model along with ratios such as TN:TP and OM:OP were used to derive concentrations of other constituents such as $\mathrm{N}$ species and OM for the Klamath River upstream boundary. 
Upper Klamath Lake is commonly accepted to be historically eutrophic (Eilers and others, 2003; Bradbury and others, 2004). Total P concentrations commonly are used to classify the trophic status of a lake, and many classification criteria are based on results from an Organization for Economic Co-Operation and Development (OECD) study of more than 200 lakes (OECD, 1982; Wetzel, 1983, 2001; Reynolds, 2006). The annual average TP concentration from the 1995 UKL TMDL model $(0.023 \mathrm{mg} / \mathrm{L})$ would be classified as mesotrophic using the OECD fixed-boundary classification criteria (mesotrophic: $0.010-0.035 \mathrm{mg} / \mathrm{L}$; eutrophic 0.035-0.100 mg/L), but near the mesotrophic/eutrophic boundary according to a classification scheme by Welch and Jacoby (2004). Using an alternate OECD classification scheme with overlapping categories, the annual average TP concentrations from the UKL TMDL model indicate a lake in the mesotrophic to eutrophic range (fig. 11). The trophic classification, however, is less important than the loads of OM, algae, and nutrients predicted by the UKL TMDL model and used as upstream boundary conditions for the Klamath River TMDL models.

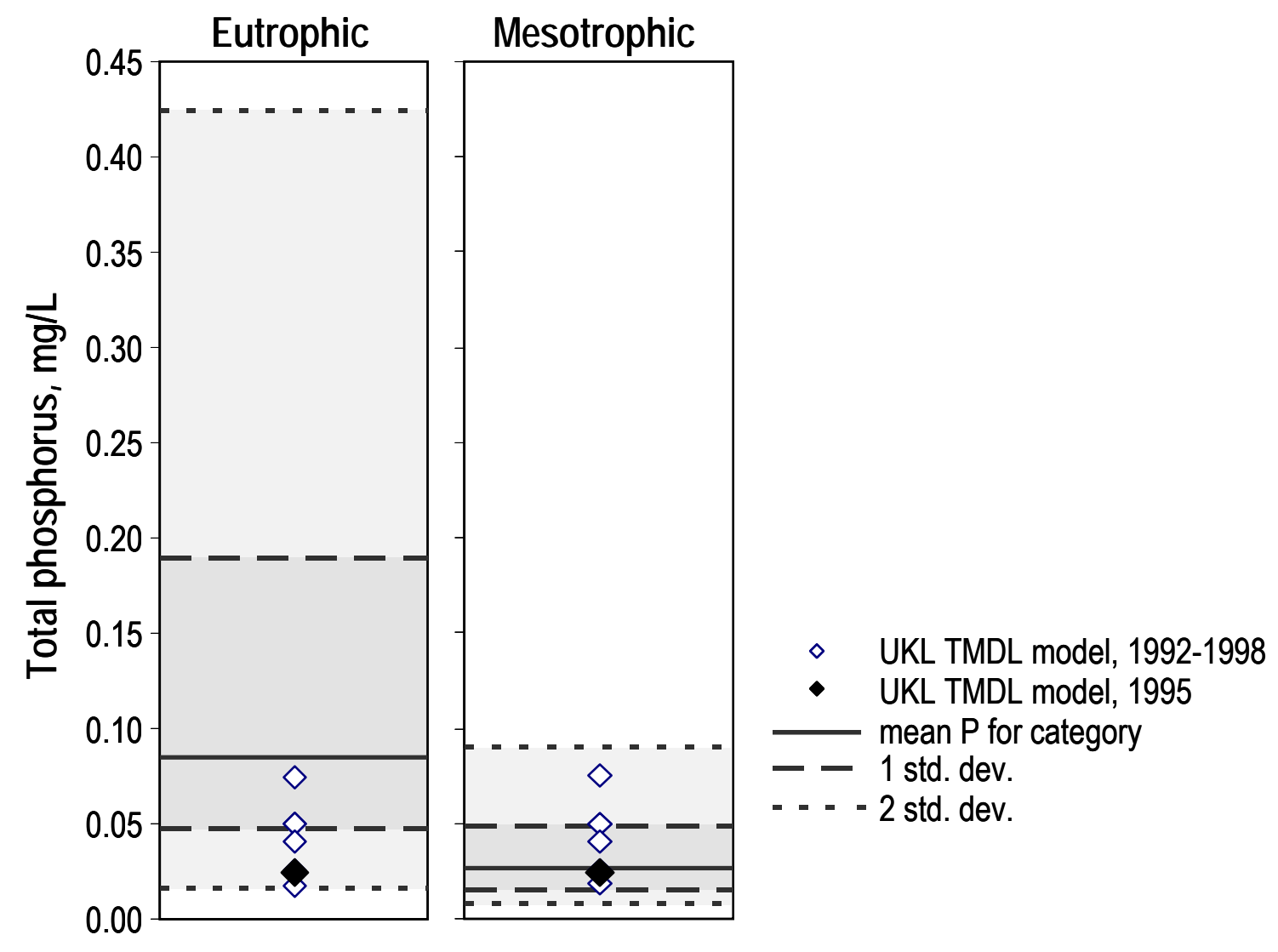

Figure 11. Graphs showing total phosphorus mean and 1- and 2-standard deviations for the eutrophic and mesotrophic OECD lake classifications (Organization for Economic Co-Operation and Development, 1982). The annual average total phosphorus outflow concentration from the 1995 Upper Klamath Lake (UKL) TMDL model's 40-percent load reduction scenario, used to develop the boundary condition for the Klamath River TMDL model, is plotted along with values from the model for 1992-98 (Walker, 2001).

Total P and OM concentrations used as the upstream boundary conditions for the natural conditions scenario seem too low, relative to what might be expected from a lake system with extensive surrounding wetland systems, peat soils, and a regional groundwater system containing 
high concentrations of P. It is beyond the scope of this review, however, to evaluate the accuracy, uncertainties, strengths, or limitations of the UKL TMDL model from which these boundary conditions were derived, or to develop an alternative estimate. The UKL TMDL model was identified by ODEQ as the largest source of uncertainty to the natural conditions model scenariolarger than uncertainties inherent to the river model and its various algorithms and parameters (Oregon Department of Environmental Quality, 2010). Given the low TP concentrations and the strange seasonal pattern in OM that result, we concur that the upstream boundary conditions are a large source of uncertainty to the natural conditions scenario. To address this increased uncertainty, additional model scenarios could be run to assess the effects of different upstream boundary conditions for the natural conditions scenario, thus providing useful insights for downstream water quality and for assessing other implications, such as the effect on TMDL allocations. In addition, future efforts to create an updated model of algal growth and nutrient cycling in UKL, in light of the data collection and research that has been performed in the last decade, would be beneficial to downstream water-quality planning and management efforts for the Klamath River.

\section{Remaining Issues}

Although many changes were made to the Link-to-Keno Klamath River TMDL models, some important issues identified in the 2009 USGS model review by Rounds and Sullivan (2009) remain. This report does not include new discussions of all remaining issues that were identified in the 2009 model review, such as the number of years simulated, any concerns about the model bathymetry, or the ammonia inputs in the year 2000 current conditions scenario. Several remaining issues are sufficiently important or noteworthy, however, to be included in this review of the revised models, and are the subject of this section of the report.

\section{Boundary Conditions}

- Organic matter. The current conditions models still specify an upstream boundary condition for OM from UKL such that 20 percent was assumed to be dissolved and 80 percent was assumed to be particulate (comment A5-Rounds and Sullivan, 2009). Both forms were given identical decomposition rates, but a substantial fraction of the particulate form will settle out downstream, leaving a smaller load of OM to be transported through the remainder of the model reach.

Recent data indicate that a large fraction of the incoming OM load (other than live algae) is in the dissolved form (Sullivan and others, 2008, 2009). Although those data were not collected during the years of interest (2000 and 2002), they do provide useful information that could be used to revise the assumptions used to partition the model OM inputs into dissolved and particulate fractions. The draft TMDL document states that this sort of information could be used to refine the model and reduce uncertainties in the upstream boundary conditions in the future (Oregon Department of Environmental Quality, 2010). Organic matter is a large and important input to the Klamath River from UKL, and is a critical constituent affecting DO concentrations, nutrient loads, and light extinction.

- TDS inputs. The TDS boundary input for the Klamath Straits Drain for the current conditions scenarios is still set to a constant $0 \mathrm{mg} / \mathrm{L}$ (comment A3-Rounds and Sullivan, 2009). This is not a particularly important concern, as this problem would have only a minor effect on water density and $\mathrm{pH}$ computations. Still, it seems inconsistent that the TDS boundary conditions for this tributary were revised for the natural conditions scenario (increased from 0 to $100 \mathrm{mg} / \mathrm{L}$ ) but not for the current conditions scenarios. 


\section{Model Source Code}

- Code version. Version 3.12 of CE-QUAL-W2, originally dated August 15, 2003, was used as the basis for the Lake Ewauna to Keno Dam model of the Klamath River for this TMDL effort. Tetra Tech modified portions of the code to add new capabilities and customize outputs. A detailed examination of the model source code was included in the 2009 USGS model review (section CRounds and Sullivan, 2009).

It is important to note, for the benefit of future model users, that errors are present in this version of the model source code, which was originally developed by the Corps of Engineers and Portland State University (Cole and Wells, 2002). Most, if not all, of the errors identified in the 2009 USGS model review do not affect the model results as long as the model user does not choose to use certain model options that currently are unused. Should the model be altered for another purpose, however, a user might unknowingly select and attempt to use a piece of the model that is broken. To that end, here is an abbreviated list of "knobs that should not be turned" in the model:

- Do not use, or do not increase the amount of, P sorption (PARTP, currently 0.001).

- Do not turn on ice calculations without correcting problems associated with the WINTER variable.

- Do not increase the sedimentary OM decomposition rate (SEDK or SDK) from its current value of zero, as parts of the SEDIMENTS subroutine are broken.

- The flux output computations currently are turned off and should not be trusted if they were to be turned on, as that part of the model code is broken. This does not affect the model simulations-just one means of extracting information from the model.

The presence of these errors in the code, as well as the fact that it is easy to make mistakes in setting up and using these models, means that if these models are to be modified or used for other purposes, it would be prudent to have the altered models run by, or reviewed by, modelers that have experience with these tools.

\section{Model Parameters}

- Algae. The revised model retained the depiction of one type of algae that is split into two groups-a "healthy" group and an "unhealthy" group that is stressed as a result of exposure to low DO conditions. The only revision to this part of the model was that the user-specified rates at which members of the healthy group become unhealthy, and vice versa, and the dependence of those rates on the DO concentration, were changed for epiphyton so that the rates and functions would be identical to those used for phytoplankton (discussed previously in section "Model Changes"). The rest of the healthy/unhealthy depiction of the algal communities remains the same as in the original models.

This healthy/unhealthy representation of the algal community continues to raise questions and concerns relative to (a) its validity with regard to instream processes, (b) the number of calibration parameters, and (c) the values selected for some of the required model parameters (comment D1Rounds and Sullivan, 2009). These issues do not mean that the model did not or cannot reproduce some of the more important patterns in the data, nor do these issues mean that the model cannot be used for certain purposes. From the perspective of scientists trying to understand the details of instream processes that occur in the Klamath River and simulate those processes with models, however, this healthy/unhealthy representation is both intriguing and troubling. Although it is interesting to postulate that the algal community might respond differently when exposed to low 
concentrations of DO, no published research is available to indicate that algae are stressed by DO concentrations in the range of 3-6 mg/L. Some variation in the response of the algal community could be modeled by breaking the algae into several groups corresponding to the different types of algae present in the river (blue-greens, diatoms, etc.), but algal speciation data were not available for 2000 and 2002. The growth, respiration, excretion, and mortality rates of the modeled algae already are dependent on water temperature, and the growth rate depends on factors such as light intensity and the concentrations of $\mathrm{N}$ and $\mathrm{P}$. It is an interesting, but still unproven, hypothesis that the algae change their response as a function of the DO concentration. To determine whether that is actually happening, detailed research to quantify that response and incorporate it into models would be needed.

Whether it is physiologically accurate to model the current condition of the algal community in the Klamath River with the postulated healthy/unhealthy approach is subject to debate and future research. In the meantime, however, several issues could be addressed to make the approach more reasonable. For example, the unhealthy algae were simulated with growth and respiration rates of zero, even during oxic conditions. This does not seem plausible; small nonzero rates would be more reasonable. In addition, the rate of conversion of phytoplankton (but not epiphyton) from healthy to unhealthy still has a cut-off at $6 \mathrm{mg} / \mathrm{L}$ that is set in the model source code (fig. 12). The reason for this cut-off, as well as its absence for epiphyton, has not been adequately explained. Furthermore, the DO dependence of the healthy to unhealthy conversion rate allows for a significant health-status conversion at relatively high DO concentrations. No published research was found during the course of this review to suggest that some fraction of the algae community should become stressed at a DO concentration of 5 or $4 \mathrm{mg} / \mathrm{L}$. The healthy/unhealthy hypothesis might be more reasonable if the conversion thresholds were set at lower DO concentrations.

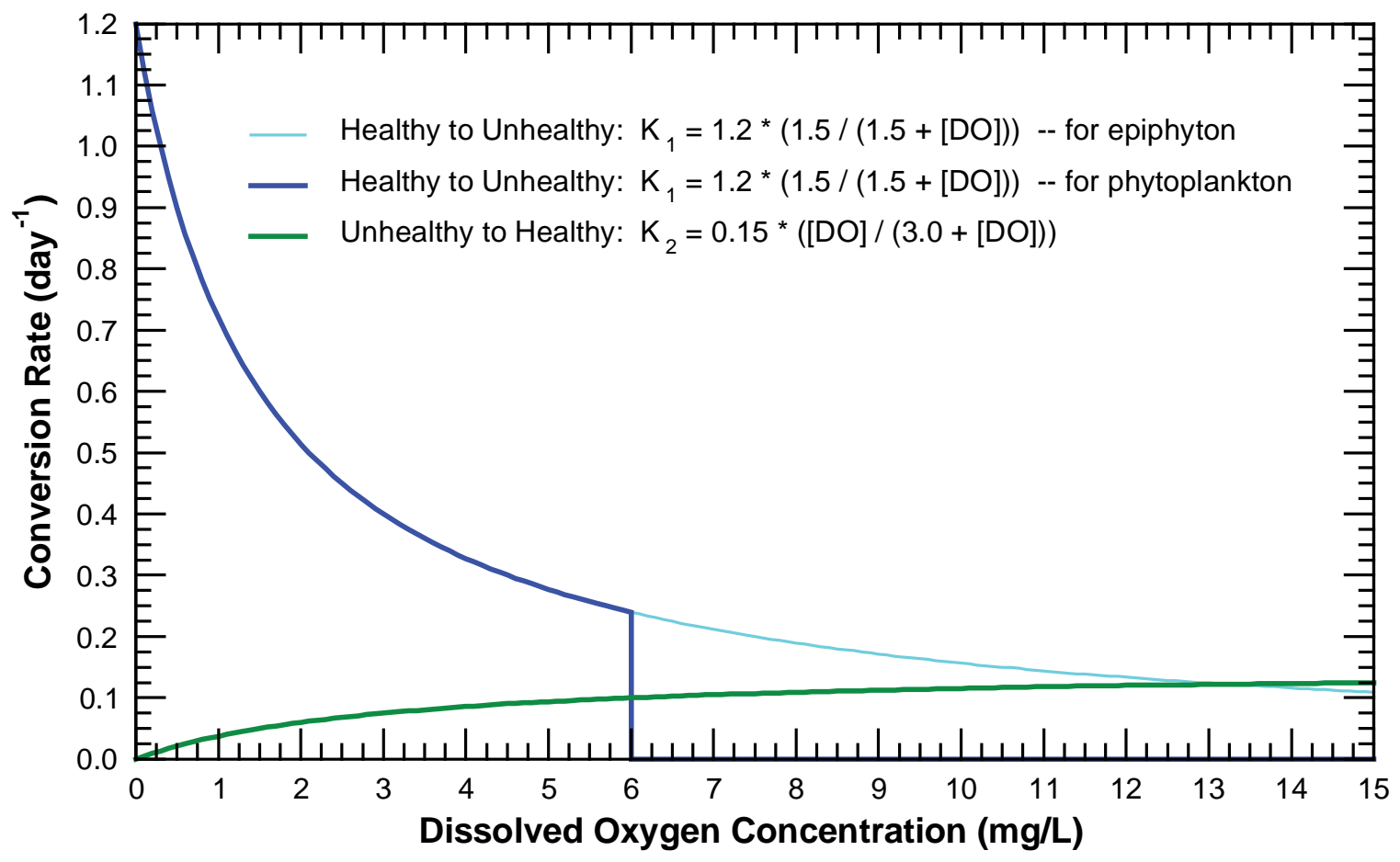

Figure 12. Graph showing simulated conversion rates from "healthy" to "unhealthy" algae $\left(\mathrm{K}_{1}\right)$ and back $\left(\mathrm{K}_{2}\right)$ for phytoplankton and epiphyton in the Klamath River TMDL model for Lake Ewauna to Keno Dam, Oregon. The $\mathrm{K}_{1}$ rate for phytoplankton is zero when the dissolved oxygen concentration is greater than $6 \mathrm{mg} / \mathrm{L}$. 
- Organic matter decomposition rates. Most of the OM in the Lake Ewauna to Keno Dam model is in the form of either labile DOM or labile POM, and the specified decomposition rates for those groups were identical (comment D3-Rounds and Sullivan, 2009). Recent research indicates that DOM in the Klamath River probably is more refractory (decomposes more slowly) than POM (Sullivan and others, 2010). The TMDL modeling effort may not have had sufficient data to add this level of complexity, but future modeling efforts definitely should make use of this recent research. This need is recognized in the draft TMDL document (Oregon Department of Environmental Quality, 2010).

\section{Model Results}

- Nitrate calibration. The 2009 USGS review noted that nitrate concentrations from the year 2000 current conditions scenario at Keno had an unexpected seasonal pattern relative to other years, with modeled summer concentrations approaching $1 \mathrm{mg} / \mathrm{L}$ (comment E3-Rounds and Sullivan, 2009). In contrast, the long-term ODEQ dataset from that site, including year 2000, shows consistently low summer nitrate concentrations. The year 2000 dataset used for model calibration did include nitrate data at Keno approaching $2 \mathrm{mg} / \mathrm{L}$ in summer, but those data may not have been reliable- the revised model documentation notes that those nitrate data are suspected to be incorrect (Tetra Tech, Inc., 2009a). The available nitrate data at Keno during 2002 showed low concentrations during summer, more similar to the historical datasets.

The revised model still predicts relatively high mid-summer nitrate concentrations at Keno in 2000 and 2002 (fig. 13). The increased nitrate concentrations in July-September 2002 for the revised model as compared to the original model are a direct result of the change in O2LIM from 2.0 to 0.1 $\mathrm{mg} / \mathrm{L}$, which caused a large increase in the rate of nitrification (conversion of ammonia to nitrate). An important fraction of the ammonia in the river during July-September 2002 probably was being released from sediments as a result of low DO conditions - the model was set up to release nutrients (ammonia and dissolved P) from the sediments as a fraction of the zero-order SOD rate when DO concentrations in the overlying water are near zero. If modeled nitrate concentrations are too high compared to measured concentrations, one or more processes likely are not being accurately modeled. The release rate of ammonia from sediments under low DO conditions may be too high, the rate of denitrification may be too low, and/or the rate of $\mathrm{N}$ uptake by algae may be too low. The model includes two mechanisms to remove nitrate through denitrification, and only one of those mechanisms was being used in the model. Future model refinements might benefit from a reexamination and adjustment of these processes in the model. 

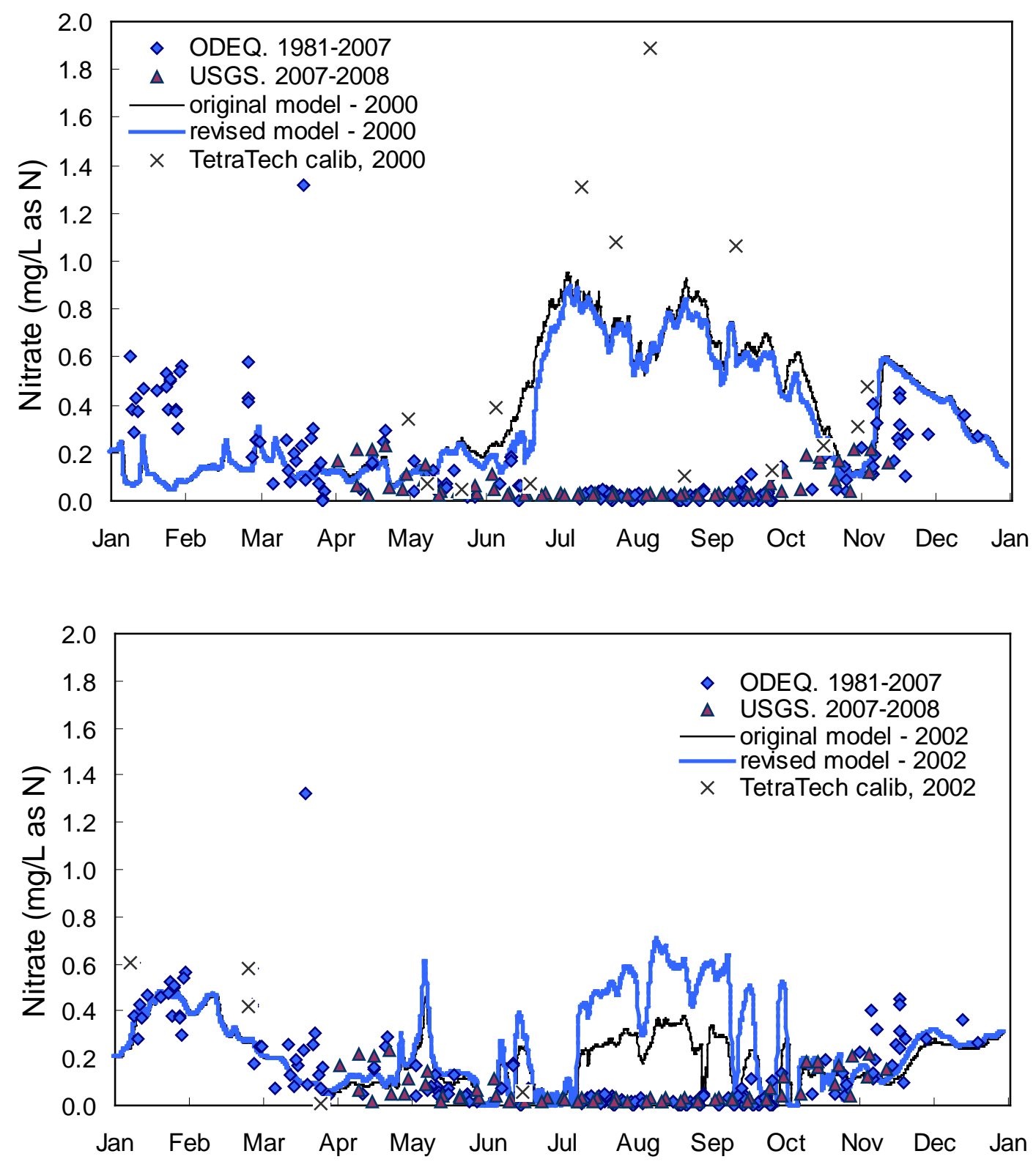

Figure 13. Graphs showing measured and simulated nitrate concentrations in the Klamath River at Keno (Highway 66). ODEQ data were collected approximately six times per year, and only data reported in units of $\mathrm{mg} / \mathrm{L}$ as nitrogen are plotted. USGS data were collected weekly from April to November during 2007 and 2008. Measured concentrations labeled "Tetra Tech calib" were used for model calibration.

Note that the revised nitrate model results at Keno (Highway 66) for 2002 in the previous figure were extracted from the model results, but are not the same as results included in the revised model documentation (Tetra Tech, Inc., 2009a, fig. E-58, p. E-25). Apparently, that figure in the model documentation, as well as a few others (fig. E-55 on p. E-24, for one), still show results from the original model rather than from the revised model. 
Natural Conditions Scenario

- Natural conditions boundary flows. Withdrawals through the North and Ady Canals were retained in the natural conditions scenario, but at slightly different flow rates compared to the year 2000 conditions on which the scenario was based. The 2009 USGS model review questioned why these withdrawal rates were different from those in the current conditions scenario (comment F1—Rounds and Sullivan, 2009). The boundary inflows for the natural conditions scenario from Link River, the Lost River Diversion Channel, and the Klamath Straits Drain all were identical to the flows used in the year 2000 current conditions scenario, but the flows for the North and Ady Canal withdrawals were not (fig. 14). This point is not particularly important relative to other choices made for the natural conditions scenario, and the discrepancy might be unintentional; regardless, better documentation would be useful.
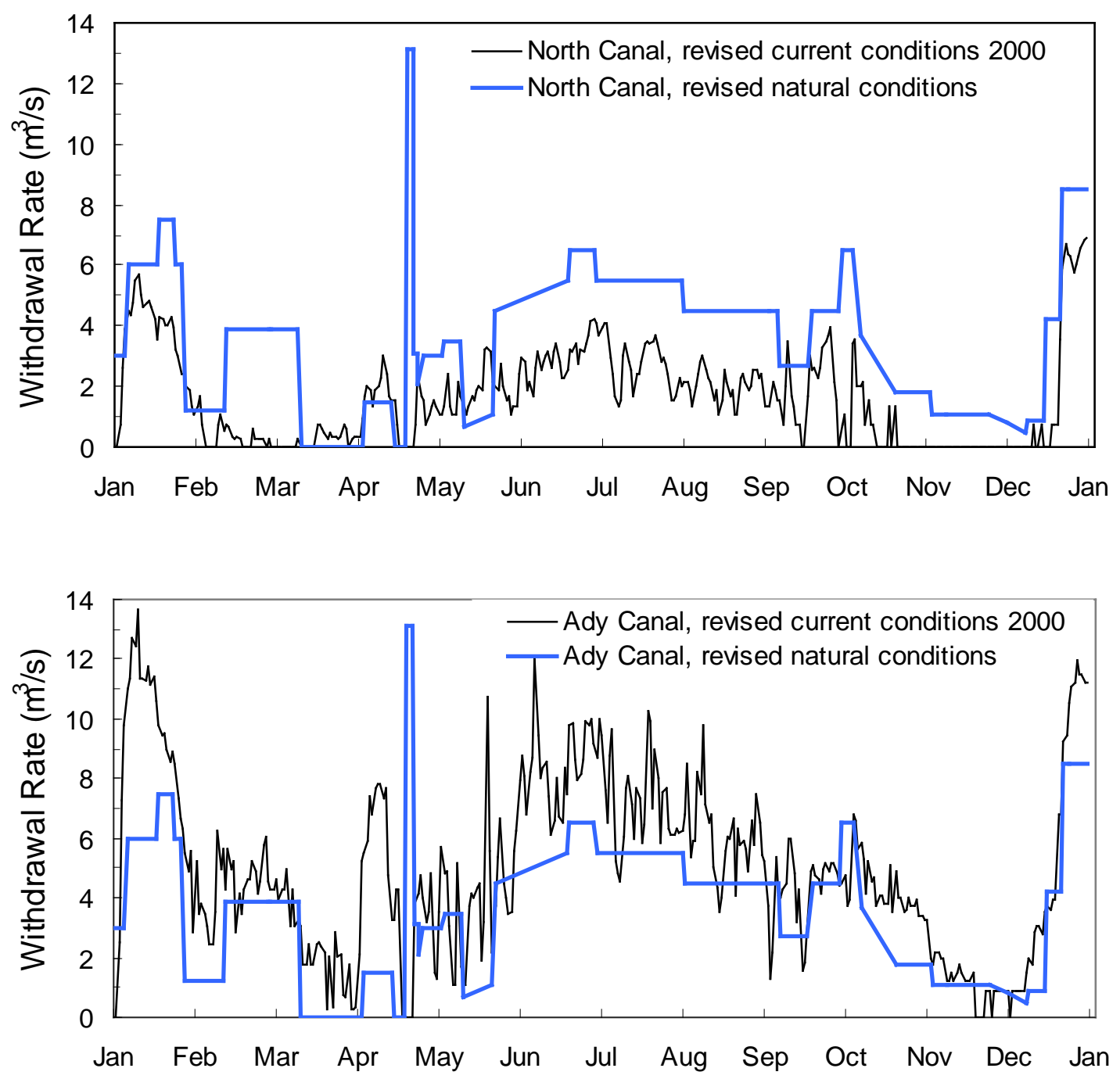

Figure 14. Graphs showing simulated withdrawal rates for the North and Ady Canals for the natural conditions scenario and the year 2000 current conditions scenario. 


\section{Perspectives on Water-Quality Modeling}

Water-quality models are simplified representations of real-world systems that are used to provide insights and help answer questions related to the management, regulation, or inner workings of those systems. For every question asked, a certain amount of uncertainty can be tolerated in the answer. Uncertainty is inherent in all model predictions, and an evaluation of that uncertainty is an important step in the modeling process. Simple questions may require only simple models. For more detailed and demanding questions, the acceptable level of uncertainty may decrease, often compelling the use or construction of more accurate, and often more complex, models. Increasing the capability and utility of a model, and decreasing its predictive uncertainty begins with ensuring that (a) the model includes algorithms describing the most important physical, chemical, and biological processes occurring in the waterbody of interest and (b) those mathematical algorithms are as accurate and robust as possible (or necessary). These assurances are particularly important when studying the details of instream processes or asking questions that are likely to include an extrapolation to conditions that are at or beyond the limits of model calibration.

Uncertainty in model predictions derives from many sources, such as incomplete or inaccurate or overly simplistic model algorithms, unrealistic or otherwise incorrect values for model parameters, and measurement or other errors in boundary conditions that propagate through the model, among others. Quantifying model uncertainty becomes increasingly difficult as the number of model parameters increases and the time required to run the model increases. A series of simulations demonstrating the sensitivity of model predictions to a few model parameters or selected boundary conditions is useful, but a full quantification of potential uncertainty for a model with hundreds of input parameters, even if only a handful are particularly important, may be impractical. Because model uncertainty is so difficult to quantify for complex models, an assessment of model algorithms, model parameter values, and boundary conditions often is the best means of assessing predictive uncertainty. For these reasons, this model review focused on the details of model algorithms, the values of model parameters, and the choice or derivation of boundary conditions. Any application of the model then must evaluate the level of acceptable uncertainty in light of the likely model error and other sources of uncertainty.

The goals and perspectives of the USGS reviewers might be different from those who developed and used the model for the Klamath River TMDL. Insights and quantitative assessments required from the models by the TMDL team have an associated tolerance for uncertainty, just as they would for any other purpose. If the perceived level of uncertainty was sufficiently high, then the Clean Water Act requires TMDLs to account for that uncertainty by choosing options that were more protective of aquatic life through a margin of safety. The draft TMDL document recognizes many sources of uncertainty, but the greatest source of uncertainty was attributed not to the models but to the upstream boundary conditions, either because of insufficient data for the current conditions scenarios, or uncertainties derived from the UKL TMDL model for the natural conditions scenario (Oregon Department of Environmental Quality, 2010). Although the model results for the TMDL may have been primarily driven by the boundary conditions, the details of the model remain important. First, the model processes those boundary conditions, simulating changes in water quality as water traverses the system. Those changes can be simulated accurately only if the model is well calibrated and its algorithms are sufficiently robust to handle some level of extrapolation. Second, the TMDL models could be used for other purposes; if so, the model must represent the most critical instream processes as accurately as possible, and all known weaknesses and uncertainties must be well documented. For both of these reasons, this review focused on some of the finer details of the Klamath River models, despite the fact that some uses of the models might be less reliant on the model parameter values and algorithms and more reliant on the choice of upstream boundary conditions. 


\section{Acknowledgments}

The authors thank Jon Hicks, Jason Cameron, and Rick Carlson of the Bureau of Reclamation for helpful discussions and feedback on the report. For providing the models, source code, and documentation, and for participating in useful discussions pertaining to this review, the authors thank Dan Turner and Steve Kirk of the Oregon Department of Environmental Quality; Mark Filippini, Ben Cope, and Sue Keydel of the U.S. Environmental Protection Agency; Clayton Creager of the California North Coast Regional Water Quality Control Board; and Andrew Parker and Rui Zou of Tetra Tech, Inc. Acknowledgment of any of these participants in discussions related to this review does not imply their agreement with the conclusions stated by USGS in this review.

\section{References Cited}

Bradbury, J.P., Colman, S.M., and Reynolds, R.L., 2004, The history of recent limnological changes and human impact on Upper Klamath Lake, Oregon: Journal of Paleolimnology, no. 31, p. 151-165.

California North Coast Regional Water Quality Control Board, 2010, Appendix 10—Public comments and responses on the staff report, appendices to the staff report, and basin plan amendment language: Santa Rosa, California North Coast Regional Water Quality Control Board, [variously paged], accessed May 12, 2010, at http://www.waterboards.ca.gov/northcoast/water_issues/programs/tmdls/klamath_river/100427/Appe ndix_10_IntroductionToRTC.pdf

CH2M-Hill and Wells, S.A., 1995, Water quality model of the Klamath River between Link River and Keno Dam: Draft report for the Oregon Department of Environmental Quality, [variously paged].

Cole, T.M., and Wells, S.A., 2002, CE-QUAL-W2-A two-dimensional, laterally averaged, hydrodynamic and water-quality model, version 3.1: U.S. Army Corps of Engineers, Instruction Report EL-02-1, [variously paged].

Doyle, M.C., and Lynch, D.D., 2005, Sediment oxygen demand in Lake Ewauna and the Klamath River, Oregon, June 2003: U.S. Geological Survey Scientific Investigations Report 2005-5228, 14 p., accessed April 5, 2010, at http://pubs.usgs.gov/sir/2005/5228/pdf/sir2005-5228.pdf

Eilers, J., Kann, J., Cornett, J., Moser, K., and St. Amand, A., 2003, Paleolimnological evidence of change in a shallow hypereutrophic lake-Upper Klamath Lake, Oregon, USA: Hydrobiologia, v. 520, p. 7-18.

Eilers, J.M., and Raymond, R., 2005, Sediment oxygen demand in selected sites of the Lost River and Klamath River-Prepared for Tetra Tech, Inc., by MaxDepth Aquatics, Inc., 17 p., accessed April 5, 2010, at http://www.deq.state.or.us/WQ/TMDLs/docs/klamathbasin/uklost/KlamathLostDraftAppendixE.pdf

Hoilman, G.R., Lindenberg, M.K., and Wood, T.M., 2008, Water quality conditions in Upper Klamath and Agency Lakes, Oregon, 2005: U.S. Geological Survey Scientific Investigations Report 20085026, 44 p., accessed April 5, 2010, at http://pubs.usgs.gov/sir/2008/5026/.

King, I.P., 2002, RMA2-A two-dimensional finite element model for flow in estuaries and streams, update documentation, version 7.0a: Fairfield, California, Resource Management Associates, October 2002, 70 p.

King, I.P., 2003, RMA11-A three-dimensional finite element model for water quality in estuaries and streams, update documentation, version 4.0a: Fairfield, California, Resource Management Associates, January 2003, 90 p. 
Mrazik, S., 2006, Oregon water quality index summary report, water years 1996-2005: Oregon Department of Environmental Quality, DEQ06-LAB-0029-TR, 13 p.

Oregon Department of Environmental Quality, 2010, Draft Upper Klamath and Lost River subbasins Total Maximum Daily Load (TMDL) and water quality management plan (WQMP): Oregon Department of Environmental Quality, [variously paged], accessed April 5, 2010, at http://www.deq.state.or.us/WQ/TMDLs/docs/klamathbasin/uklost/KlamathLostTMDLWQMP.pdf

Organization for Economic Co-Operation and Development, 1982. Eutrophication of watersMonitoring, assessment and control: Report of the OECD Cooperative Programme on Eutrophication, Prepared by Vollenweider, R.A. \& J. Kerekes, OECD, Paris, 154 p.

Raymond, R., and Eilers, J.M., 2004, Sediment oxygen demand and nutrient release from sites in Lake Ewauna and Keno Reservoir-Prepared for PacifiCorp by MaxDepth Aquatics, Inc., 18 p.

Reynolds, C.S., 2006, Ecology of phytoplankton: Cambridge University Press, New York, 550 p.

Risley, J.C., and Rounds, S.A., 2006, Evaluation and review of recent Klamath River water-temperature modeling studies: U.S. Geological Survey Administrative Letter, 27 p.

Rounds, S.A., 2007, Temperature effects of point sources, riparian shading, and dam operations on the Willamette River, Oregon: U.S. Geological Survey Scientific Investigations Report 2007-5185, 34 p., accessed April 5, 2010, at http://pubs.usgs.gov/sir/2007/5185/.

Rounds, S.A., and Doyle, M.C., 1997, Sediment oxygen demand in the Tualatin River Basin, Oregon, 1992-1996: U.S. Geological Survey Water-Resources Investigations Report 97-4103, 19 p, accessed April 5, 2010, at http://pubs.er.usgs.gov/usgspubs/wri/wri974103.

Rounds, S.A., and Sullivan, A.B., 2009, Review of Klamath River total maximum daily load models from Link River Dam to Keno Dam, Oregon: U.S. Geological Survey Administrative Report, 37 p., accessed April 5, 2010, at http://or.water.usgs.gov/proj/keno_reach/download/klamath_river_model_review_final.pdf

Rounds, S.A., and Wood, T.M., 2001, Modeling water quality in the Tualatin River, Oregon, 19911997: U.S. Geological Survey Water-Resources Investigations Report 01-4041, 53 p., accessed April 5, 2010, at http://or.water.usgs.gov/pubs_dir/Online/Pdf/01-4041.pdf

Sullivan, A.B., Deas, M.L., Asbill, J., Kirshtein, J.D., Butler, K., and Vaughn, J., 2009, Klamath River water quality data from Link River to Keno Dam, Oregon, 2008: U.S. Geological Survey Open-File Report 2009-1105, 25 p., accessed April 5, 2010, at http://pubs.usgs.gov/of/2009/1105/.

Sullivan, A.B., Deas, M.L., Asbill, J., Kirshtein, J.D., Butler, K., Wellman, R.W., Stewart, M.A., and Vaughn, J., 2008, Klamath River water quality and acoustic Doppler current profiler data from Link River Dam to Keno Dam, 2007: U.S. Geological Survey Open-File Report 2008-1185, 24 p., accessed April 5, 2010, at http://pubs.usgs.gov/of/2008/1185/.

Sullivan, A.B., and Rounds, S.A., 2005, Modeling hydrodynamics, temperature and water quality in Henry Hagg Lake, Oregon, 2000-2003: U.S. Geological Survey Scientific Investigations Report 2004-5261, 38 p., accessed April 5, 2010, at http://pubs.usgs.gov/sir/2004/5261/.

Sullivan, A.B., and Rounds, S.A., 2006, Modeling water-quality effects of structural and operational changes to Scoggins Dam and Henry Hagg Lake, Oregon: U.S. Geological Survey Scientific Investigations Report 2006-5060, 36 p., accessed April 5, 2010, at http://pubs.usgs.gov/sir/2006/5060/.

Sullivan, A.B., Rounds, S.A., Sobieszczyk, S., and Bragg, H.M., 2007, Modeling hydrodynamics, water temperature, and suspended sediment in Detroit Lake, Oregon: U.S. Geological Survey Scientific 
Investigations Report 2007-5008, 40 p., accessed April 5, 2010, at http://pubs.usgs.gov/sir/2007/5008/.

Sullivan, A.B., Snyder, D.M., and Rounds, S.A., 2010, Controls on biochemical oxygen demand in the upper Klamath River, Oregon: Chemical Geology, v. 269, no. 1-2, p. 12-21, doi: 10.1016/j.chemgeo.2009.08.007, accessed April 5, 2010, at http://dx.doi.org/10.1016/j.chemgeo.2009.08.007.

Tetra Tech, Inc., 2009a, Model configuration and results-Klamath River model for TMDL development: Prepared for U.S. Environmental Protection Agency Region 9 and 10, North Coast Regional Water Quality Control Board, Oregon Department of Environmental Quality, Fourth revision, December 2009, [variously paged], accessed April 5, 2010, at http://www.deq.state.or.us/WQ/TMDLs/docs/klamathbasin/uklost/KlamathLostDraftAppendixC.pdf

Tetra Tech, Inc., 2009b, Modeling scenarios_-Klamath River model for TMDL development: Prepared for U.S. Environmental Protection Agency Region 9 and 10, North Coast Regional Water Quality Control Board, Oregon Department of Environmental Quality, December 2009, [variously paged], accessed April 5, 2010, at http://www.deq.state.or.us/WQ/TMDLs/docs/klamathbasin/uklost/KlamathLostDraftAppendixD.pdf

Thurman, E.M., 1985, Organic geochemistry of natural waters: Durdrecht, The Netherlands, Nijhoff/Junk Publishers, 497 p.

Walker, W.W., Jr., 2001, Development of a phosphorus TMDL for Upper Klamath Lake, Oregon: Prepared for Oregon Department of Environmental Quality, March 7, 2001, accessed April 5, 2010, at http://www.deq.state.or.us/wq/TMDLs/docs/klamathbasin/ukldrainage/devphostmdl.pdf

Watercourse Engineering, Inc., 2004, Klamath River modeling framework to support the PacifiCorp Federal Energy Regulatory Commission Hydropower Relicensing Application, March 9, 2004.

Welch, E.B., and Jacoby, J.M., 2004, Pollutant effects in freshwater-Applied limnology, $3^{\text {rd }}$ edition: Spon Press, New York, 520 p.

Wetzel, R.G., 1983, Limnology: Saunders College Publishing, Philadelphia, 860 p.

Wetzel, R.G., 2001, Limnology_Lake and river ecosystems: Academic Press, San Diego, 1006 p.

Wood, T.M., 2001, Sediment oxygen demand in Upper Klamath and Agency Lakes, Oregon, 1999: U.S. Geological Survey Water-Resources Investigations Report 01-4080, 13 p, accessed April 5, 2010, at http://or.water.usgs.gov/pubs_dir/WRIR01-4080/wri014080.pdf 


\section{Appendix A. Qualifications of Reviewers}

USGS is the Nation's largest water, earth, and biological science and civilian mapping agency. The USGS collects, monitors, analyzes, and provides scientific data and interpretations about natural resource conditions, issues, and problems. With no regulatory or resource management mission, USGS provides unbiased and impartial research and scientific information to resource managers, planners, and other customers.

A detailed model review of this type is best performed by scientists who have extensive waterquality modeling expertise, experience with the specific models under review, and knowledge of the water body being modeled. The two USGS hydrologists who performed this review meet these criteria and are currently working with the CE-QUAL-W2 model and the reach of interest of the Klamath River.

Dr. Stewart Rounds has been using CE-QUAL-W2 to model water quality in the rivers and lakes of Oregon for 18 years, including models that have formed the foundation of TMDL regulations in the Tualatin and Willamette Rivers (Rounds and Wood, 2001; Rounds, 2007). Dr. Rounds is well versed with the CE-QUAL-W2 source code and has collaborated with the model developers on model improvements. Dr. Rounds’ professional page may be viewed at https://profile.usgs.gov/sarounds/.

Dr. Annett Sullivan currently leads a project designed to better understand instream water-quality processes in the Link River Dam to Keno Dam reach of the Klamath River and improve upon existing models of that reach. She has more than 8 years of experience working with CE-QUAL-W2 on river and reservoir systems in Oregon, and has published detailed USGS modeling reports using CE-QUAL-W2 on Detroit Lake, Henry Hagg Lake, and the Santiam and North Santiam River systems in Oregon (Sullivan and Rounds, 2005, 2006; Sullivan and others, 2007). Dr. Sullivan’s professional page may be viewed at https://profile.usgs.gov/annett. 